\title{
International Collaboration and European Contributions to International Business Research
}

\author{
Rachida Aïssaoui $^{1} \cdot$ J. Michael Geringer ${ }^{1} \cdot$ Grigorios Livanis $^{1}$
}

Received: 27 January 2020 / Revised: 25 November 2020 / Accepted: 22 December 2020 /

Published online: 12 January 2021

(c) The Author(s), under exclusive licence to Springer-Verlag GmbH, DE part of Springer Nature 2021

\begin{abstract}
This study measures and ranks the performance of nations and academic institutions based on a 45-year analysis of international business (IB) publications, including 5853 academic authors from 1542 affiliated institutions. Examining authors' academic origin and university of affiliation, and with a focus on the European nations that participated in the production of IB research, we make several novel contributions to the field: (1) identifying a unique internationalization process of IB research that consists of three distinct stages driven by international collaboration, (2) highlighting the role of international collaborations in overcoming publication barriers at the regional and country level, and (3) highlighting the role of both scale and scope of international collaborations in achieving a top-ranked position in the production of IB research.
\end{abstract}

Keywords International collaboration · International business · Internationalization · Resource dependency $\cdot$ Research

\section{Introduction}

Several recent bibliometric studies have shown that international business (IB) research has become geographically diversified, with increased mobility of researchers across borders. Simultaneously, while still a major producer of research, North American dominance in IB journal publications has evidenced a relative decline, partly a reflection of increased output by authors in Europe (Aïssaoui and Geringer 2018; Chan et al. 2006; Ellis and Zhan 2011; Geringer and von Glinow 1999; Kothari and Lahiri 2012; Lahiri and Kumar 2012; Ryazanova et al. 2017; Trevino et al. 2010; Xu et al. 2014). While most studies report on the Americanization of IB research (Mangematin and Baden Fuller 2008; Üsdiken 2014), this recent redistribution of relative geographic dominance between

Grigorios Livanis

g.livanis@ohio.edu

1 College of Business, Ohio University, Athens, OH, USA 
American and European institutions begs the question of whether Europeanization of IB research is a reflection of the American model of "publish or perish" (Miller et al. 2011; Wilson 1942) or whether, instead, we are observing a fundamental transformation of the field where dynamic new clusters of IB research activity are emerging, often in conjunction with cross-border and inter-regional collaborations.

A key finding of prior literature is that acceptance of the "publish or perish" model for achieving academic career success has not been equal across nations (Üsdiken 2004; Viiu et al. 2016). Low penetration or adaptation of this performance model in some nations or regions has been attributed to different causes, including attaching importance to non-English language publications (e.g., national or regional), different publication outputs being more prestigious (e.g., books rather than journals), or emphasis on different epistemologies than the positivist approach common to North American research (Eden and Rynes 2003; Hicks 2012; Lopez-Navarro et al. 2015). Another strand of the literature identifies nations' and institutions' resource constraints as a central motivation to adopt this model. Such constraints range from economic factors, such as the need to access costly and unique databases, to networking and conference participation, editorial board diversity, and English language skills (Chinchilla-Rodriguez et al. 2018; Harzing and Metz 2012, 2013; Horn 2017; Ribeiro et al. 2018).

Yet another strand of the literature suggests that increased international collaboration and mobility is contributing to proliferation of the "publish or perish" model (Jonkers and Cruz-Castro 2013; Lages et al. 2015). This finding is largely echoed in research assessing the evolution of published IB research output, which points to a clear Americanization of academic practices (de Rond and Miller 2010; Tsui 2007). For instance, Xu et al. (2014) and Aïssaoui and Geringer (2018) find that development of IB research in the Asia-Pacific region was largely supported by extensive collaboration between Asia-Pacific and North American academic institutions. Specifically, Aïssaoui and Geringer (2018) note how hiring research stars from the U.S.- - and the U.K.- represented a key strategy among Asia-Pacific universities as they sought to jumpstart their position as leading global actors in IB research.

Together, these studies agree that increased collaboration (Jonkers and CruzCastro 2013; Kirkman and Law 2005) and increased internationalization (Leonidou et al. 2010; Ryazanova et al. 2017) have contributed to the emergence of both European and Asian academic institutions as central actors in the global arena for publication of scholarly research (Ellis and Zhan 2011; Trevino et al. 2010). However, these studies also lament a continued under-representation of research from Africa, Latin America, and the Middle East (Kirkman and Law 2005; Lages et al. 2015). Importantly, the asserted unequal representation that favors North American research has been widely criticized for social phenomena in general, and international and intercultural phenomena specifically, as being highly contextual and thus requiring search for both etic and emic explanations (Leung 2009, 2012).

Our study explores the evolution of IB research by European academic institutions. Our focus on Europe is motivated by the relative dearth of bibliometric studies focused on the region, a rather surprising situation given the central role played 
by European researchers and academic institutions in the evolution of IB research. For instance, European research tends to favor interpretivist approaches (Baruch 2001; Lopez-Navarro et al. 2015) whose decided advantage is their insistence on the importance of context, and thus their ability to shed light on contextual and institutional factors in cross-national and cross-cultural variations (Kostova 1997, 1999; Peng 2002).

Furthermore, we cover the period from 1971 to 2015, which allows us to trace the evolution of the European region and its academic institutions since the initial years of IB journals and to contrast European trends with those of other regions. Our database includes 5853 authors from 1542 affiliated institutions involved in producing 5508 qualifying publications. Findings from this study contribute to both our understanding of resource dependencies in academic research and the role of international collaboration on research performance, notably by identifying that different types of international collaboration may be at play in supporting research productivity. Specifically, this study's contributions include: (1) identifying a unique internationalization process of IB research that consists of three distinct stages driven by international collaboration, (2) highlighting the role of international collaborations in overcoming publication barriers at the regional and country level, and (3) highlighting the role of both scale and scope of international collaborations in achieving a top-ranked position. The next section discusses the evolution of IB research, including globalization of "publish or perish" practices and international research collaboration. The discussion then turns to this study's research methodology, followed by presentation and discussion of results. The final section presents our study's conclusions and potential limitations.

\section{Americanization of Research Practices in IB: Challenges and Opportunities for European Research}

\subsection{Globalization of "Publish or Perish" Practices}

Bibliometric studies have widely adopted peer-reviewed articles in leading journals as their favored unit of analysis to assess research performance (Adler and Harzing 2009; Usdiken 2014), since they are argued to "introduce a measure of objectivity into the evaluation of scientific literature" (Zupic and Cater 2015). Results from these analyses help assess the evolution of a field, both quantitatively and qualitatively, and assist in identifying constraints to a field's development and key institutional sources for research performance (Tuselmann et al. 2016). Importantly, bibliometric analyses are instrumental in recruitment, selection, and resource allocation decisions, among others (Aithal 2016; Hall 2001). In the U.S., successful publishing in academic journals is a common consideration in tenure and promotion decisions (Bedeian et al. 2010; Glick et al. 2007) and it influences both financial rewards (Bird 2006) and resource allocation (Hall 2001). The practice commonly known as "publish or perish" to measure academic success (Miller et al. 2011) has been widely adopted in other regions. Lahiri and Kumar (2012), for instance, show how the "publish or perish" practice has been institutionalized in Europe and Asia. 
Adoption of a "publish or perish" approach, as has occurred in most of Europe (Hicks 2012), is not without challenges or resistance. An excellent review of major roadblocks against institutionalization of this model is provided in a symposium series by the Journal of Management Inquiry, led by Behlül Üsdiken (2004). Although conducted nearly two decades ago, the symposium's authors offer an in-depth historical overview of ways in which European nations implemented this practice, often adapting it to fit their own needs and definitions of quality research: Engwall (2004) focuses on Scandinavian nations, Kieser (2004) on Germany, Tiratsoo (2004) on Britain (see also Hewitt-Dundas 2012), and Kipping et al. (2004) on Mediterranean Europe. These studies trace the Americanization of this academic standard first to post-World War II relationships between Europe and the U.S., more pointedly to the Marshall Plan in a resource-constrained region (Hewitt-Dundas 2012), and later to policies driven by the European Commission (Hewitt-Dundas 2012; Viiu et al. 2016).

Importantly, these studies reveal wide heterogeneity in practice adoption, which Kipping et al. (2004), Mangematin and Baden-Fuller (2008), and Hicks (2012) equate to what Zilber (2006) and Sahlin and Weldin (2008) would call an institutional translation process, i.e., a process of adaptation and modification of a practice to align it with the context in which it is implemented. For instance, Hicks (2012) explains that journal lists commonly used to assess research productivity are often inadequate for universal application, which led Norway to adopt "publish or perish" but only after various adaptations. Also building on the institutional diffusion literature, Kipping et al. (2004) chronicle how Spanish academia developed a hybrid performance system. A central insight from this research is its illustration that practices often cannot achieve global adoption without some form of modification or translation (Minkov and Hofstede 2011), or 'glocalization' (Robertson 1997).

Resistance to the "publish or perish" practice for European markets is further explained by its tendency to discount non-English language publications (Eden and Rynes 2003; Hicks 2012). In addition, this performance standard can disadvantage European authors whose prestige may derive from their ability to write books more so than journal publications (Baruch 2001; Lopez-Navarro et al. 2015).

These isomorphic pressures remain very strong, though, as more and more business schools seek to increase their global legitimacy and visibility by obtaining the U.S.-based AACSB accreditation (Harzing and Metz 2013; Scherer et al. 2005; Üsdiken 2004, 2014). Stating that, "A signal should closely reflect the underlying unobservable quality for which it serves as a proxy", Ryazanova et al. (2017, p. 832) assert that insistence on journal publications as a prime indicator of research contribution largely benefits English-speaking scholars in general, and U.S. scholars in particular.

Üsdiken (2014) and Ryazanova et al. (2017) identify a strategy to address this pressure to publish, namely international collaboration and, more specifically, collaboration with English-speaking authors. In their examination of 60 years of psychological research published in American journals, Piocuda et al. (2015) note the importance, for achieving progress in that field, of international collaboration, which has the added benefit of better discriminating the emic from the universal. 


\subsection{International Collaboration and Research Performance}

Üsdiken (2014, p. 764) tests the assumption that U.S. dominance in journal publications has been decreasing, but finds instead, "a greater tendency towards the U.S.-style when educational and collaborative ties to the USA are involved". This continued dominance, the author argues, has been particularly pronounced with underrepresented nations. This is consistent with the view that international collaboration has been widely leveraged to address increasing pressures for publishing, even more so in leading journals and by non-English speaking authors (Baruch 2001; Eden and Rynes 2003). This tendency toward increased international collaboration and with an increasing number of nations is particularly visible in IB and management research, which Kirkman and Law (2005, p. 380) explain by "the complexity of international management research and the cross-nation collaboration that is characteristic of this type of research" (see also Leonidou et al. 2010).

Furthermore, international collaboration is sometimes the only viable route for emerging market authors to access valuable resources that are often required to publish in top-tier journals (Piocuda et al. 2015), making scientific relationships increasingly resource dependent (Chinchilla-Rodriguez et al. 2018). While these resources are often economic, such as the need to access costly and unique databases (Eden and Rynes 2003), other key resources include access to a network of central actors or gatekeepers in academic fields (Harzing and Metz 2013; Ryazanova et al. 2017), as well as to English-speaking authors. Networking is indeed widely recognized as facilitating research productivity (Cohen et al. 2003; Settles et al. 2006) and access to leading journals (Baruch 2001; Ribeiro et al. 2018).

Yet, despite obvious efforts by mainstream IB journals to be more inclusive, there is still evidence of a handicap for non-U.S. authors, notably by studies on editorship effects, which commonly identify a positive relationship between connection to journal editors and research output. Assessments of leading economics and finance journals, for instance, largely report that members of an editor's network publish with higher frequency (Brogaard et al. 2014; Colussi 2018; Zinovyeva and Bagues 2015). With leading journals often based in the U.S., this situation aggravates challenges faced by non-U.S. academics (Baruch, 2001) and even more so by authors from already underrepresented regions (Harzing and Metz 2013; Lopez-Navarro et al. 2015). Lages et al. (2015) explain that this bias may be fueled by editors' and reviewers' lack of knowledge about these regions. Leung (2012) adds that requirements to demonstrate generalizability of research are generally more stringent for papers based on non-U.S. data.

While not denying the existence of editor or reviewer bias and further recognizing the uneven distribution of acceptance rates by the Academy of Management Journal across regions and nations, Eden and Rynes (2003) also find that the number of submissions from Africa, southern Europe, and Latin America is also lower (see also Harzing and Metz 2013). A direct survey among nonNorth American authors revealed that reluctance to submit research to this journal stemmed from these authors' concerns that their work would not "receive a favorable review because it is 'different"' (Eden and Rynes 2003, p. 679). 
This issue has long been a challenge for European authors whose research tends to build on different epistemologies and, by extension, methodologies than what is commonly viewed as sound research in U.S. academia (Baruch 2001; Jarley et al. 1998). European research has a long tradition of an interpretivist/ constructivist approach, which often requires qualitative methods (Creswell 2009; Yilmaz 2013). In contrast, North American research favors a positivist approach and has long rejected non-quantitative methods, which are perceived as lacking objectivity (Amis and Silk 2008).

In addition to slow acceptance of non-positivist approaches (March 2005), differences have been noted with respect to research focus, preferred topics, and perspectives. Even within Europe, Hofstede (1981, p. 32) noted a wide variety in focus: "Authors from Latin Europe focus on power; from Central Europe, including Germany, on truth; from Eastern Europe, on efficiency; from Northern Europe, on change". Similarly, a difference in preferred topics was identified across nations and found to hinder Asian research innovativeness, as Asian authors tend to choose Western topics as a means to improve chances of publication (Meyer 2006; Tsui 2007). Lastly, Eden and Rynes (2003, p. 679) find that preferred perspectives also vary across regions, with European research often adopting the perspective of stakeholders beyond just managers or shareholders, as is common in North America. Bajwa and Konig (2019) add that while labor unions are often discussed in many parts of the world, they are barely covered in U.S. studies.

Together, these challenges for non-North American research help explain not only the Americanization of management research, but also the need to collaborate with North American authors, which in turn perpetuates the Americanization of IB research (Mangematin and Baden-Fuller 2008). March (2005) and Tsui (2007) lament this paradigmatic convergence which, they argue, has led to "a paucity of high-quality context-specific, or indigenous, research" (Tsui 2007, p. 1354; see also: Leung 2009, 2012). In addition, despite continued calls for greater cultural sensitivity and cultural awareness (Doktor et al. 1991; Earley and Singh 1995), the establishment of English as the lingua franca of academic research contributes to this lack of cultural sensitivity as it may not adequately convey "local rhetorical and stylistic patterns" (Lopez-Navarro et al. 2015, p. 940).

English has indeed become an almost inescapable resource for authors seeking to publish in top management journals (Horn 2017; Lillis and Curry 2010), a situation which, in European academia, has been further encouraged by European Union policies (Kieser 2004; Modiano 2017). As a result of this linguistic standardization, those who are less English-proficient are handicapped or marginalized (Horn 2017; Lopez-Navarro et al. 2015), with Burgess et al. (2014) noting that non-native English speakers face an unfair hurdle associated with the additional time and economic resources required. This language barrier is argued to be the principal reason for low representation of non-English speaking nations in mainstream journals (Baruch 2001; Engwall 1996). Ryazanova et al. (2017, p. 834) further explain that as the "top" journals are predominantly published in English, "This makes an institution's endowment of linguistic capital a source of heterogeneity within the industry". 
Although "the majority of the world's scholars do not possess English as their first language" (Flowerdew 2008, p. 77), the proportion of articles in English by researchers whose first language is not English is increasing (Lopez-Navarro et al. 2015). This situation is strongly fueled by and motivates increased international collaboration and mobility (Abramo et al. 2018; Jonkers and Cruz-Castro 2013; Lages et al. 2015; Piocuda et al. 2015).

In sum, North American researchers enjoy what some would call an unfair advantage as their language, theories, models, and research standards have become de facto standards (Bajwa and Konig 2019; Üsdiken 2004). In the next sections, we first present our research methodology and then investigate how IB research conducted by authors in European nations has developed within this context.

\section{Research Methodology}

\subsection{Journal Selection}

As the leading IB-focused scholarly journal, we use the Journal of International Business Studies (JIBS) to identify journals to include in analyses. Specifically, each journal citation contained in the articles and research notes published in JIBS from 1980 through 1991 was counted and the 14 most highly cited journals were identified. ${ }^{1}$ This approach allowed our study to respond to calls to include general management journals in assessment of IB research productivity (e.g., Trevino et al. 2010). In addition to three IB-focused journals, namely JIBS, Management International Review, and Journal of World Business (previously Columbia Journal of World Business), eleven journals encompassing different business disciplines were identified: Academy of Management Journal, Academy of Management Review, Administrative Science Quarterly, American Economic Review, California Management Review, Harvard Business Review, Journal of Finance, Journal of Marketing, Journal of Marketing Research, Sloan Management Review, and Strategic Management Journal. ${ }^{2}$

\subsection{Article Selection}

Due to the wide variety of topics contained in the sample journals, only publications focused explicitly on IB issues were included. These publications were identified using the definition of IB developed by Nehrt et al. (1970), subsequently reiterated

\footnotetext{
$\overline{1}^{\text {The difference between the } 14^{\text {th }}}$ and $15^{\text {th }}$ highest-cited journals, Sloan Management Review and Journal of Applied Psychology, respectively, was 29.3\% (53 vs. 41 citations during the 12-year period examined). The next 6 highest-cited journals ranged from 40 to 34 citations, suggesting an appropriate breakpoint for analysis was after the top 14 highest-cited journals.

${ }^{2}$ Other IB-focused journals that may currently be recognized as prominent outlets for IB research, such as International Business Review (IBR) or Journal of International Management (JIM), were not included in this study's analysis since they were not established until 1992 and 1995, respectively.
} 
by Ricks (1985) as editorial policy at JIBS and used by Morrison and Inkpen (1991) in their study of significant IB contributions. This definition is found in "Appendix".

Using this definition, all articles and research notes published in the 14 sample journals from the beginning of 1971 to the end of 2015 were identified. Other journal contents, including case studies, monthly columns, introductions to special issues, editorials, comments and replies, and dissertation abstracts, inter alia, were excluded. This process resulted in identification of 5508 qualifying publications. This population database includes 5853 authors and 1542 affiliated institutions, both academic and non-academic, that were listed for at least one qualifying article in the sample journals during the 45-year period of study.

These publications were manually coded for author, author's institution of affiliation, geographic location of the affiliated institution, journal, journal's volume and issue, type of article, and number of authors. In addition, the Ph.D. affiliation of each author was manually coded by extracting information from each article, if available, along with searching a broad range of databases including WorldCat, Academy of International Business Directory, Dissertation Abstracts International, and LinkedIn, among other sources, supplemented with Internet searches for authors with no information in the prior databases. If authors were not holding a Ph.D., we coded any other highest scientific degree. Students in Ph.D. programs were coded as seeking to obtain the degree from the institution where they were enrolled. The sample authors obtained their Ph.D. from 637 unique institutions.

\subsection{National and Institutional Measures of Output}

To measure institution- and nation-level output, we used an approach similar to Lahiri and Kumar (2012) and Chan et al. (2006), assessing both absolute and adjusted scores. Absolute score consists of the absolute number of appearances for a given author, regardless of the author's share in the publication. Alternatively, the adjusted score considers the number of authors for an article. This is a straightforward method in line with most other studies where if $N_{i}$ is the number of authors of article $i$, then the weight assigned to each author is simply $1 / N_{i}$. For example, the listed institution and author of a sole-authored publication was credited with 1.0 point, the institutions and authors in a dual-authored paper each received 0.5 points, and so forth. An advantage of the adjusted measure over the absolute measure is that it avoids overestimation of institutions' contributions in multi-authored papers. Because the number of articles with multiple authors is increasing, using the absolute measure could bias results in favor of authors and their respective affiliations in the sample's most recent years. Results for an institution are derived by aggregating all authors who state this institution as their current affiliation at the time of publication. To get summary statistics for nations, results for institutions located in the respective nations are simply summed. 


\subsection{Measures of International Collaboration}

We measure the degree of international and inter-regional collaboration by adapting the indicators of internationalization of Abramo et al. (2018) and further refined by Abramo et al. (2019). We define International Collaboration Intensity (ICI) as the number of publications with authors from at least two different nations and interRegional Collaboration Intensity $(R C I)$ as the number of publications with authors from at least two different regions, with the regions categorized as Europe, North America, Asia Pacific, Africa, Latin America, and the Middle East. These measures are expanded to evaluate a nation's International Collaboration Rate $(I C R)$ and region's inter-Regional Collaboration Rate $(R C R)$, i.e., the proportion of articles resulting from international and inter-regional collaboration, respectively, out of the total number of articles. The scope of internationalization of IB research is represented by the number of nations with which a nation collaborates, or International Collaboration Amplitude (ICA).

\section{IB Research Productivity in Europe}

Before analyzing European IB research productivity, we describe the European Union's role in the standardization of educational practices and policies and the consequent rise in demand for English proficiency that prior studies have identified as an important factor for publishing in the leading management journals. Subsequently, we present the rankings of nations and institutions in IB research productivity, with a focus on the increasing contribution of European nations and academic institutions.

Against this backdrop, we then analyze the role of international collaboration in overcoming resource dependencies and publication barriers (e.g., English proficiency, gatekeeper ties), thereby allowing nations and, in turn, regions to develop or enhance their IB research capabilities. Focusing on the most productive European nations, we identify a process that may have contributed to highly performing European nations establishing their leading positions in global IB research. International collaboration with the leading nations, markedly the U.S., appears to be key, especially in the early stages of a nation's efforts for IB research capability development. Further, to achieve a top ranking in IB research productivity, high levels of both scale and scope of international collaboration seem justified, as we identify next. We conclude with a detailed analysis of a select set of European countries and a discussion of our results.

\subsection{European IB Research in the Global Scene: Background}

Europe hosts a large number of nations -27 of which are represented in our studywith diverse historical, religious, linguistic, and economic backgrounds. Many are part of the European Union (EU), becoming members of this political-economic union at different times. Others (Iceland, Liechtenstein, Norway, Switzerland) have 
chosen instead to unite through a trade agreement, the European Free Trade Association. These unions have been instrumental in the introduction of a wide set of standards aimed at harmonizing various aspects of members' political, legal, economic, monetary (Goerke and Holler 1998), and educational practices and policies (Enever 2012; EU Education 2020).

In education, the EU further encourages collaboration among members with such initiatives as the Erasmus exchange program, established in 1987 to promote mobility of students within the European community. Erasmus+and Erasmus Mundus expanded this practice to a wider set of educational actors and nations. These programs and policies have driven demand for English proficiency (Enever 2012), making it the most widely spoken foreign language in 19 of the 23 member states where it is not an official language.

The U.K. has traditionally held an important role in ensuring "English correctness and standardization" in Europe (Modiano 2017, p. 314). Our study reveals that the role of the U.K. as the epicenter of IB research in Europe is central in linking European research to the global IB academic community. However, with the recent Brexit, it is reasonable to ask whether the U.K. will maintain its position as both the gatekeeper of a unified English in the European region and the epicenter of IB research.

\subsection{Europe and Its Evolving Role in Global IB Research}

We examined the performance of Europe and its participating nations by aggregating data over all 45 years and for the three 15-year periods of 1971-1985, 1986-2000, and 2001-2015. ${ }^{3}$ Table 1 ranks the 20 most productive nations by academic affiliation and presents research performance for the three periods based on each nation's share of adjusted output. Figure 1 illustrates the evolution of IB research, comparing performance by academic affiliation to performance by academic origin for the most productive regions.

Our findings confirm the increasing presence of European IB research in leading journals, as previously discussed by Morrison and Inkpen (1991) who cover 9 journals from 1980 to 1989, Xu et al. (2014) who examine 23 journals from 1995 to 2011, and Ryazanova et al. (2017) who provide an analysis of IB research in 149 journals from 2007 to 2015. Europe's increasing role, along with increasing performance in the Asia-Pacific region, corresponds with a declining relative performance of the U.S. and Canada. We note, though, that Europe's upward trend began almost 15 years prior to that of Asia-Pacific, whose nations began to experience a significant rise in their rankings.

The nations driving Europe's rising role have experienced less dramatic changes. The U.K., France, The Netherlands, and Germany have maintained high rankings (from 2nd to 10th) during the three 15-year periods, being responsible for a share of the adjusted global output ranging from $1.8 \%$ for Germany to $7.6 \%$ for the U.K.

\footnotetext{
${ }^{3}$ Following the suggestion of an anonymous reviewer, we report results using 15 -year time periods. However, results are qualitatively the same when 5-year time periods are used.
} 


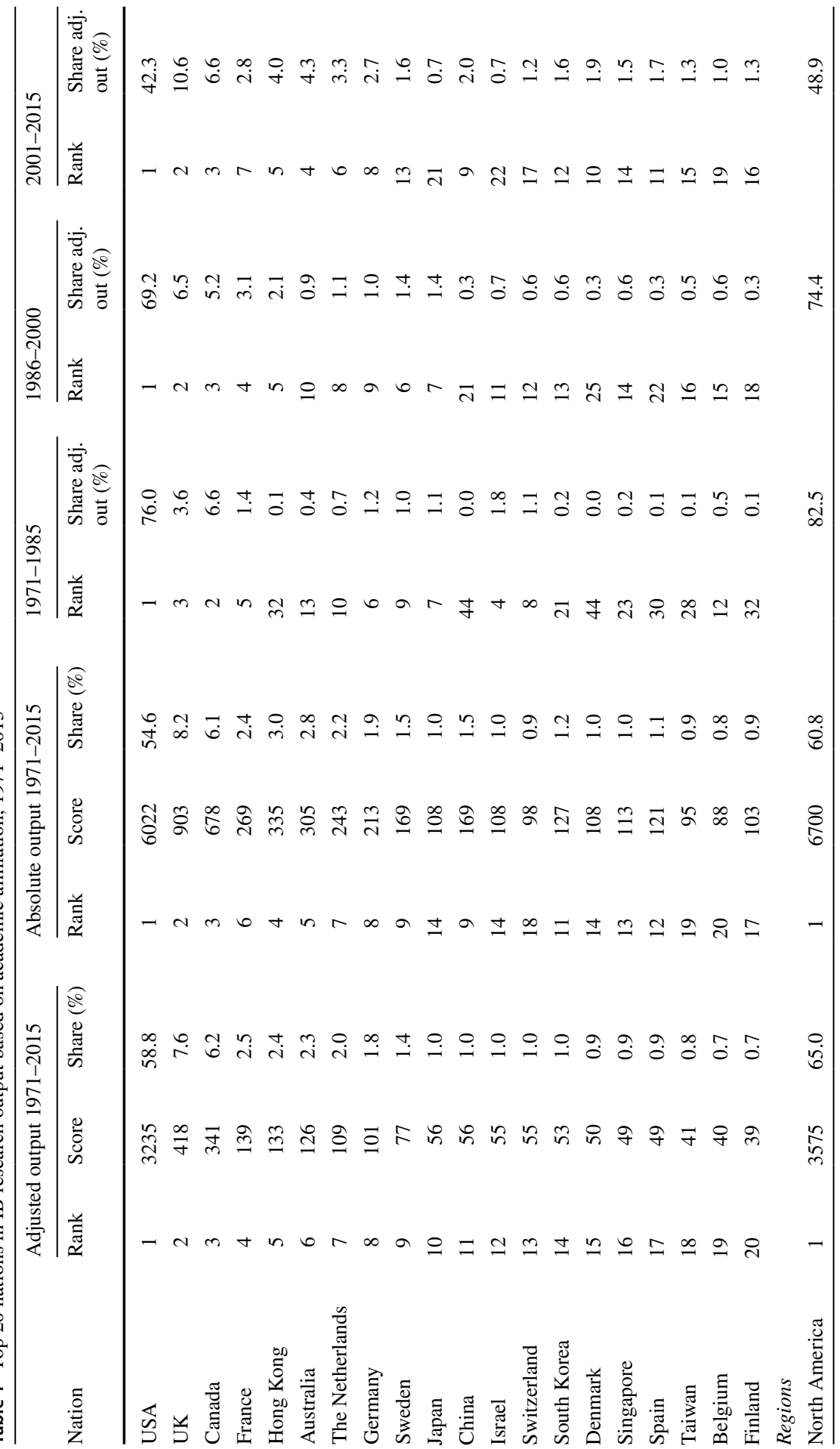




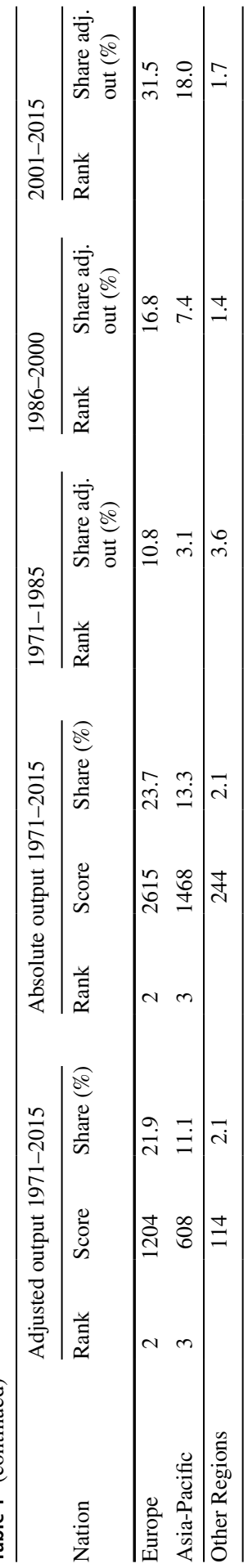




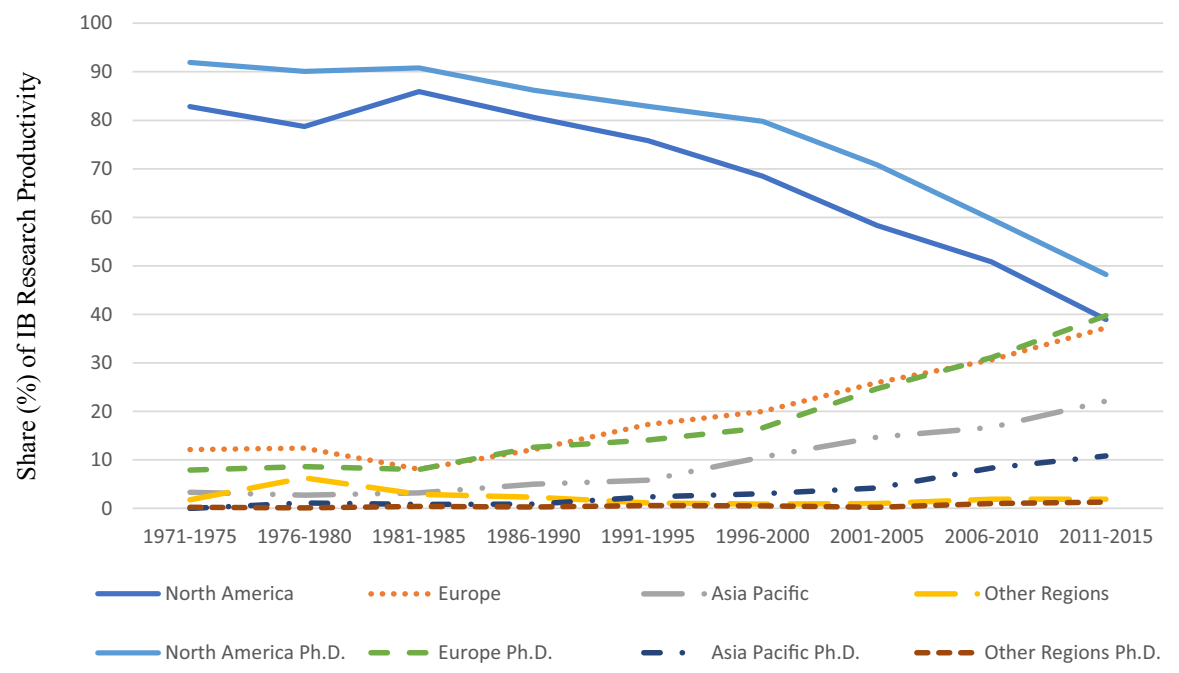

Fig. 1 Regional share of international business research productivity by academic origin and academic affiliation, 1971-2015

for the whole period (Table 1). These performances contrast sharply with the U.S. which, despite its declining share, is still responsible for almost $60 \%$ of the IB research produced globally. However, the European region as a whole experienced incredible growth, from a $10.5 \%$ share in $1971-1985$ to $31.5 \%$ in $2001-2015$, which is primarily due to the number of participating European nations increasing from 14 in the first period, to 21 in 1986-2000, and 26 in the last period (Fig. 1). In this last period, six nations (Bulgaria, Croatia, Estonia, Greece, Iceland, and Lithuania), including four socialist or post-socialist nations, published their first IB work in one of the 14 leading journals.

Europe's increasing prominence in global IB research was further supported by its role as a training center for IB research, even surpassing North America's performance in 2014 (Fig. 1). Aspiring Ph.D.s are also increasingly likely to graduate from Asia-Pacific academic institutions, whose share has begun to witness a sustained and gradual growth, from $4.2 \%$ in $2001-2005$ to $10.8 \%$ in $2011-2015$. At the same time, North American dominance in authors' academic origin declined from $70.8 \%$ to $48.2 \%$.

\subsection{Leading European Institutions in IB Research}

Table 2 ranks the 15 academic institutions with the highest adjusted output and their corresponding absolute output, for the overall and three sub-periods. Data are also provided for the number of total institutions during these periods, along with the combined shares these 15 institutions were responsible for. The role of leading academic institutions emerges as critical in driving their nation's and even region's performance. Only 31 of the 1083 academic institutions are ranked among the top 15 institutions in any one of these four periods; that is, $98.6 \%$ of the institutions 
never reached this rank. It is worth noting, however, that the rankings are volatile. With some exceptions, such as Harvard, Rutgers, and the universities of Pennsylvania and South Carolina, no institution made it to the top 15 in all four periods, only six appeared three times, and almost $70 \%$ of these leading academic institutions achieved a place in these rankings only once or twice.

Together, these leading institutions held a disproportionate share of the global production of IB research. In the first period, they accounted for only $4 \%$ of the total number of academic institutions but $34 \%$ of the adjusted output. This concentration by leading institutions remained significant in the following periods: less than $3 \%$ of institutions in 1986-2000 and 1.8\% in 2001-2015, but $29 \%$ and $19 \%$ of the global output, respectively, demonstrating that concentration among the leading institutions has persisted despite an increase in the number of institutions worldwide being involved in generating publications.

Comparatively, IB research output was even more concentrated among the top 15 European academic institutions (Table 3). Despite an increasing number of European institutions publishing in a top 14 journal, the leading 15 academic institutions represented $52.0 \%$ of the total European output in the first period, $49.0 \%$ in the second period, $37.5 \%$ in 2001-2015, and more than one of three publications for the whole 45-year period. Akin to the global rankings, some exceptions such as INSEAD, London Business School, and the universities of Reading and Uppsala appeared as leading institutions in all four periods and eight appeared three times in these rankings, with the remaining 16 institutions occupying a place in these rankings only once or twice.

These data reveal two main issues. First, while leading European academic institutions fare better than their non-North American peers who are practically absent from these rankings (Table 2), they are still performing at significantly lower levels than the highest performing North American institutions. In fact, some North American academic institutions performed even better than entire nations. Harvard was responsible for an adjusted output of 179 (3.6\%) (Table 2) for the 45-year period whereas France, despite its position as the 4th leading nation, had a score of 139 $(2.5 \%)$ (Table 1) and performed only slightly better than Columbia University and University of Pennsylvania (Table 2), each of which held a share of $2.1 \%$.

Second, volatility of these rankings warrants caution about conclusions regarding these institutions' performance. Tables 3 and 4 both show that achieving a top position during one time period does not guarantee a subsequent similar position and maintaining a top position over multiple time periods is particularly challenging. In fact, even the top 5 institutions experienced significant changes, notably as non-North American institutions began to establish prominence.

As a final point, the number of European authors publishing IB research in the leading journals increased dramatically, from 172 in 1971-1985 and 359 in 1986-2000, to 1098 authors in the last period. The equivalencies and changes for being a leading author in Europe compared to a leading author globally further reflect the increased competitiveness of European authors. Indeed, being the most productive European author in the first period did not guarantee a spot among the top 25 most prolific global authors. Only in the second period did this situation change, with four authors holding a leading position both in Europe and globally. 


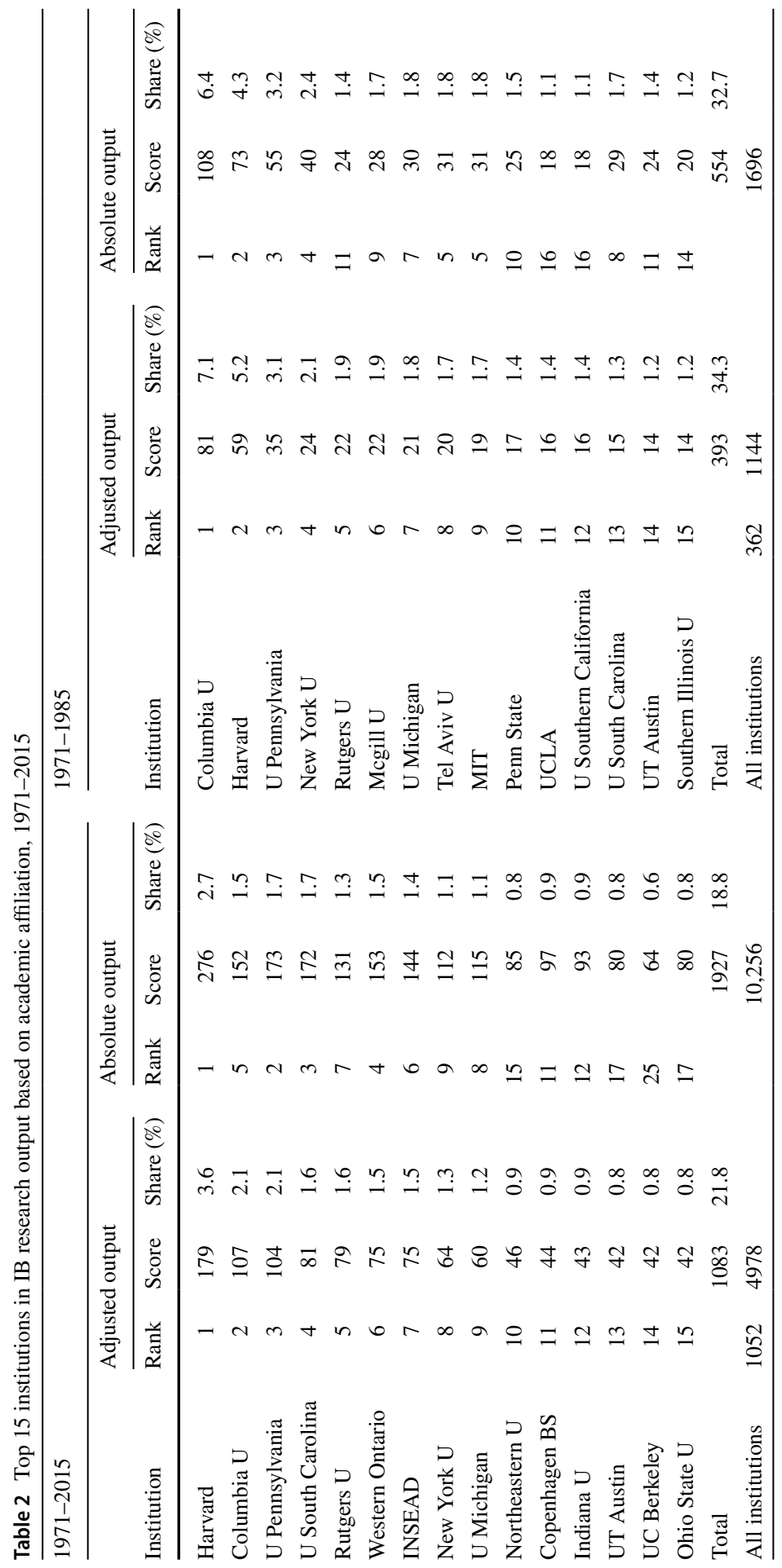




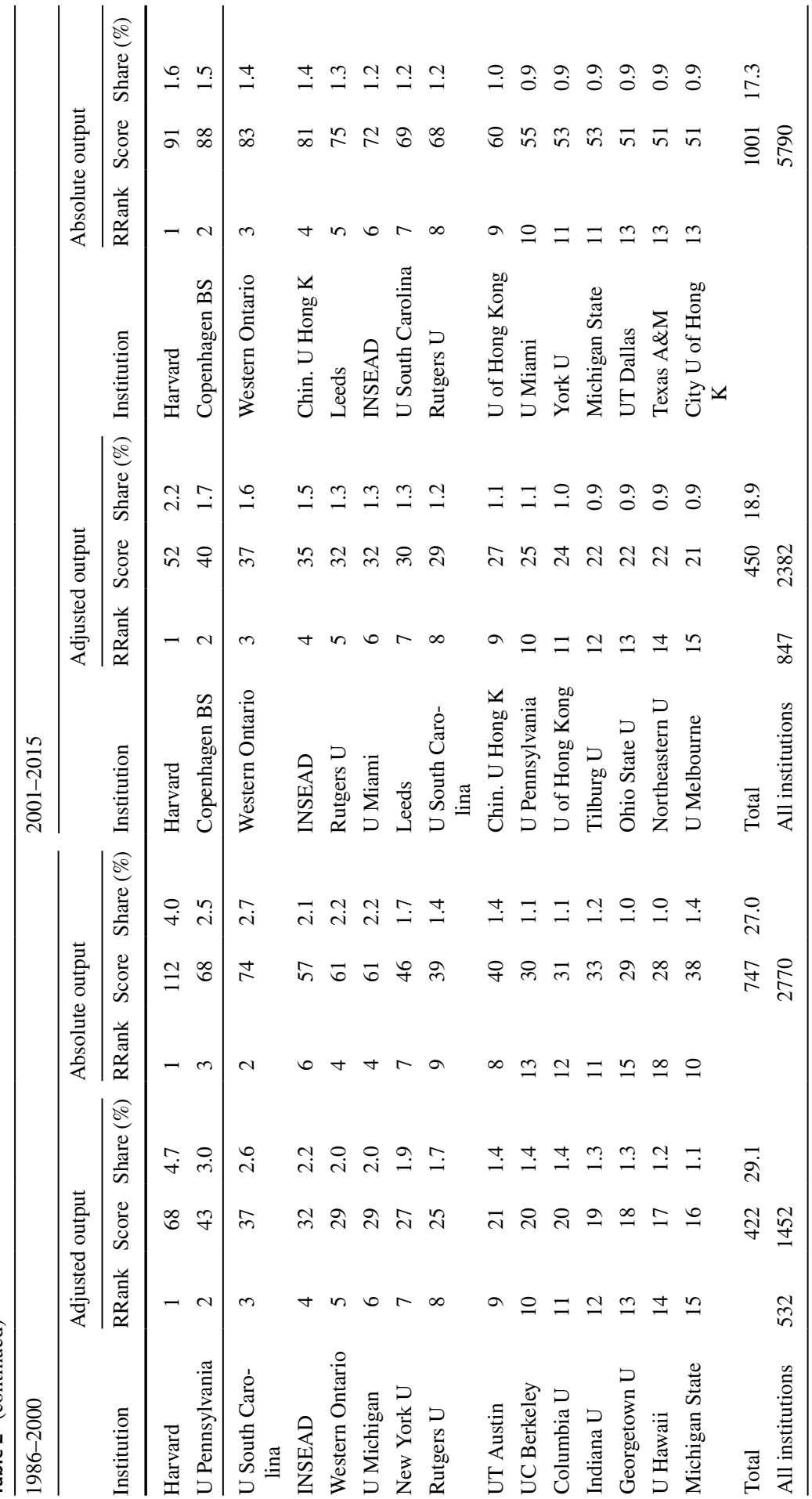




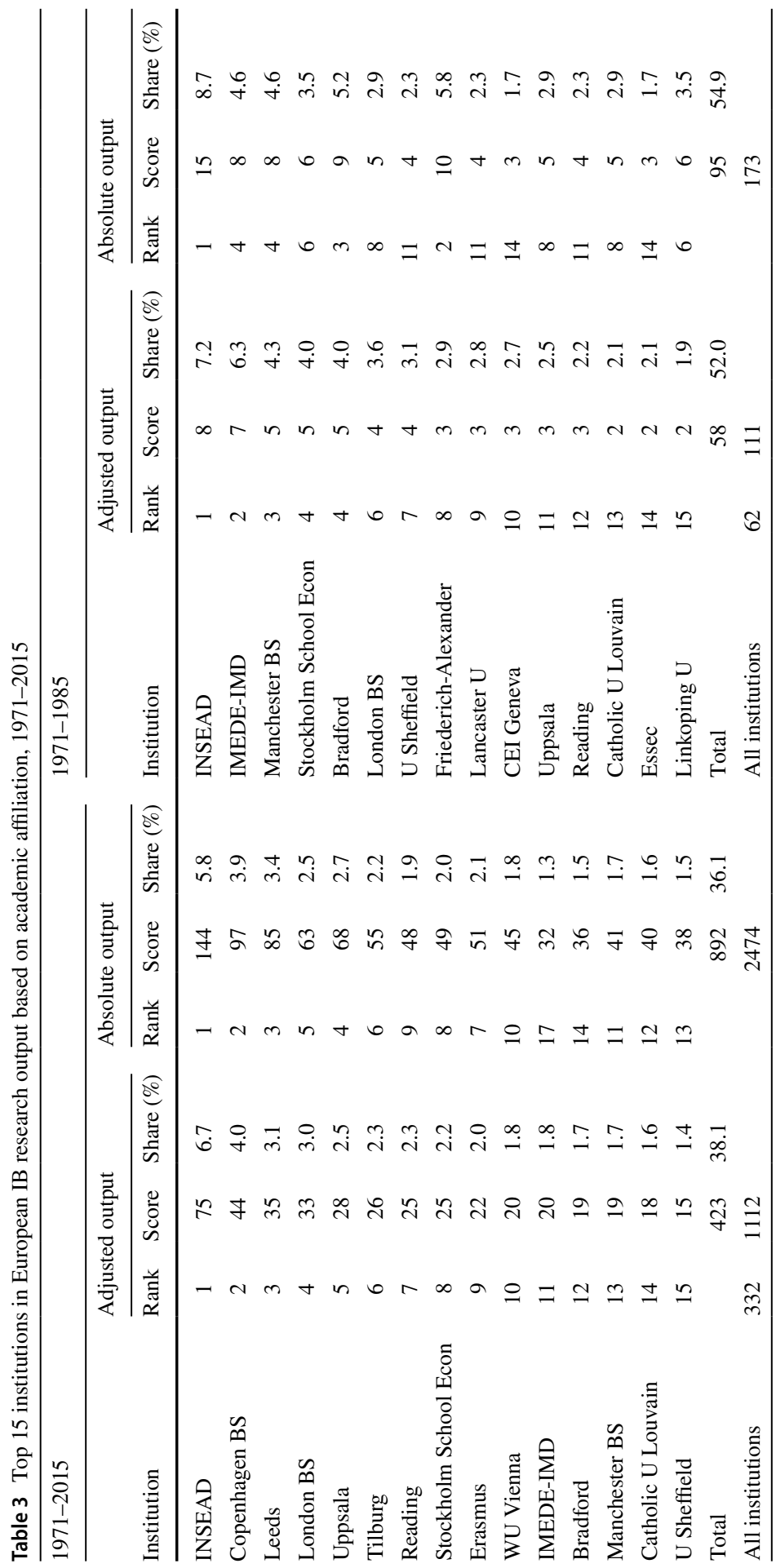




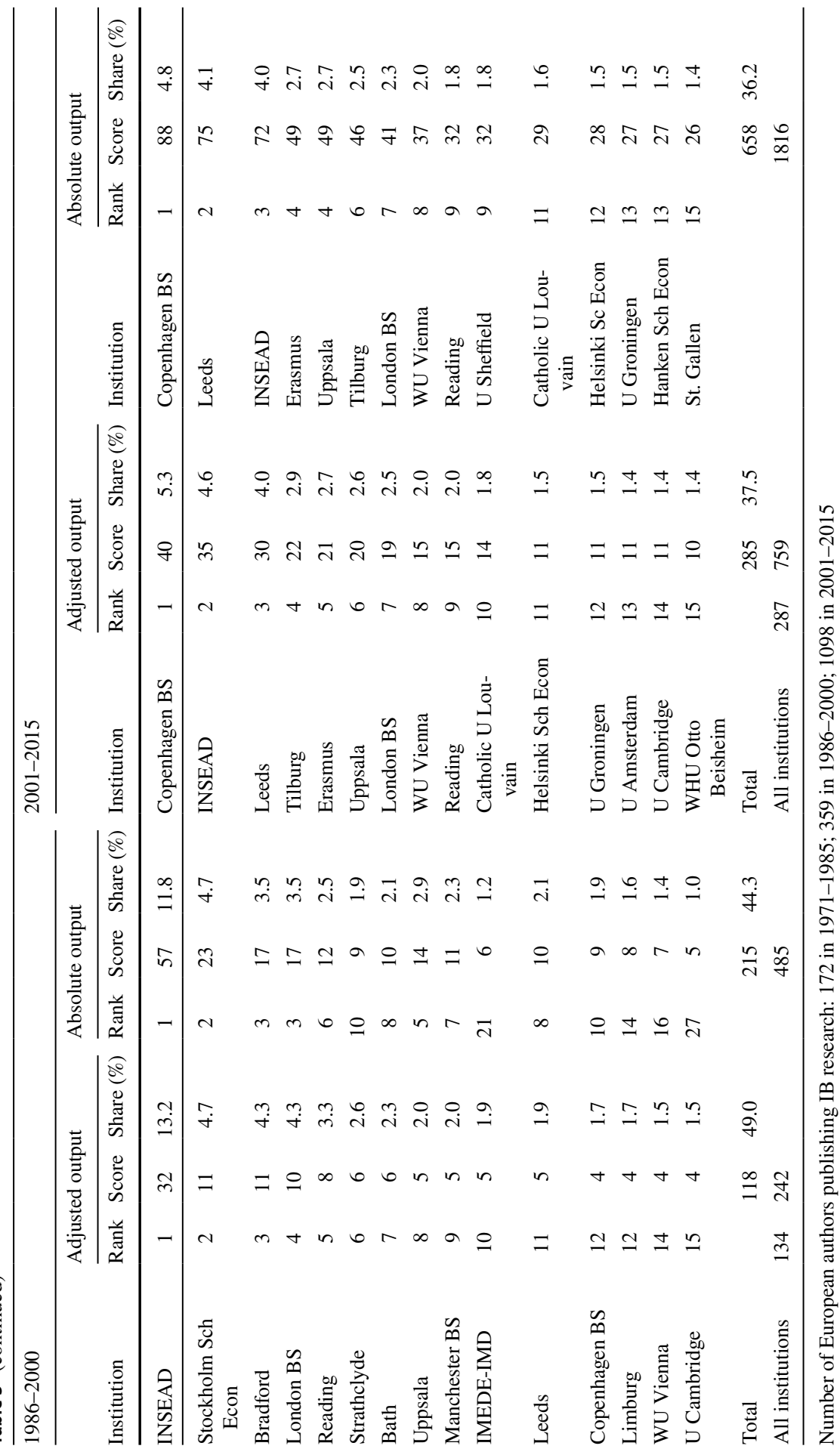




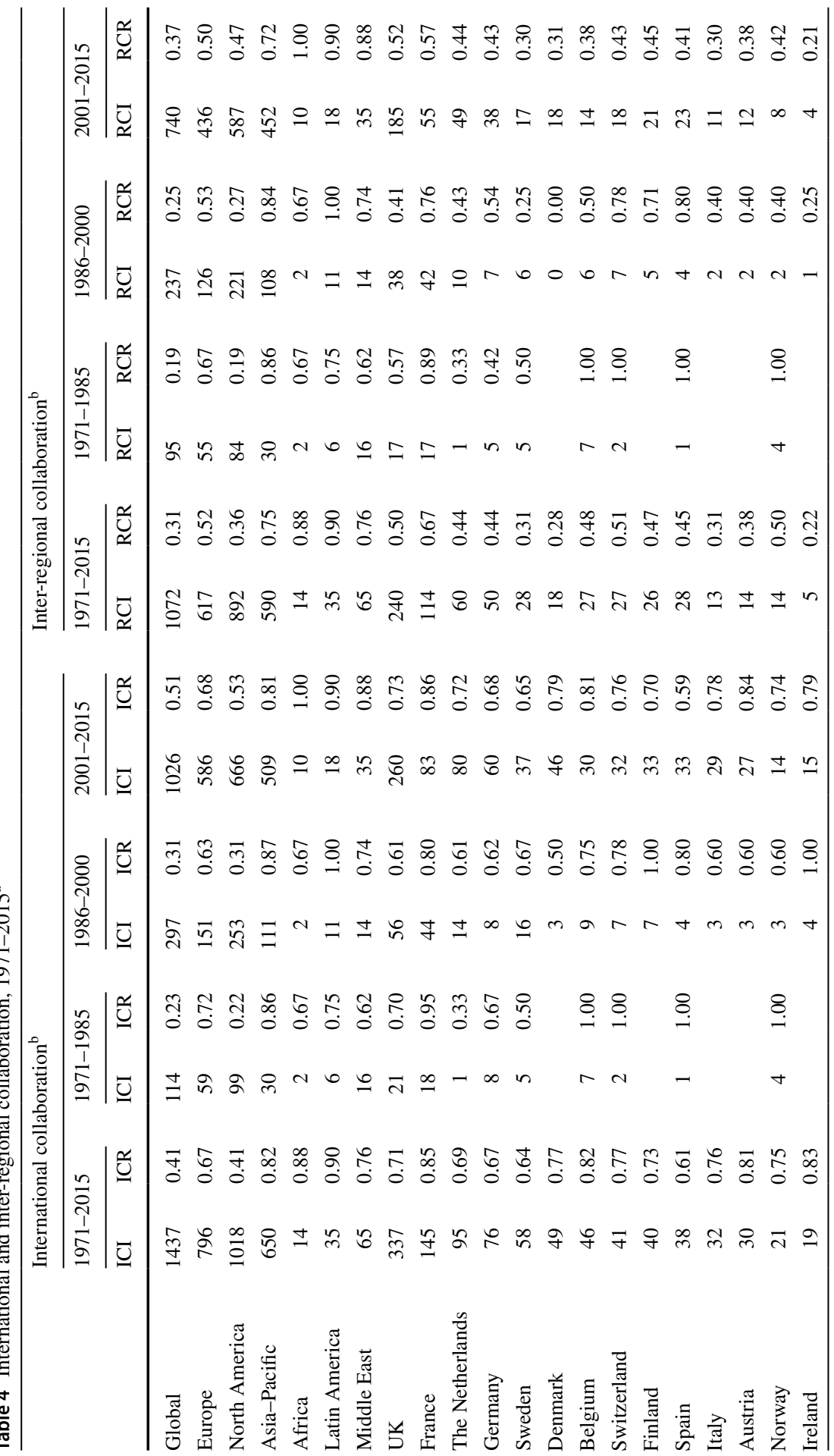




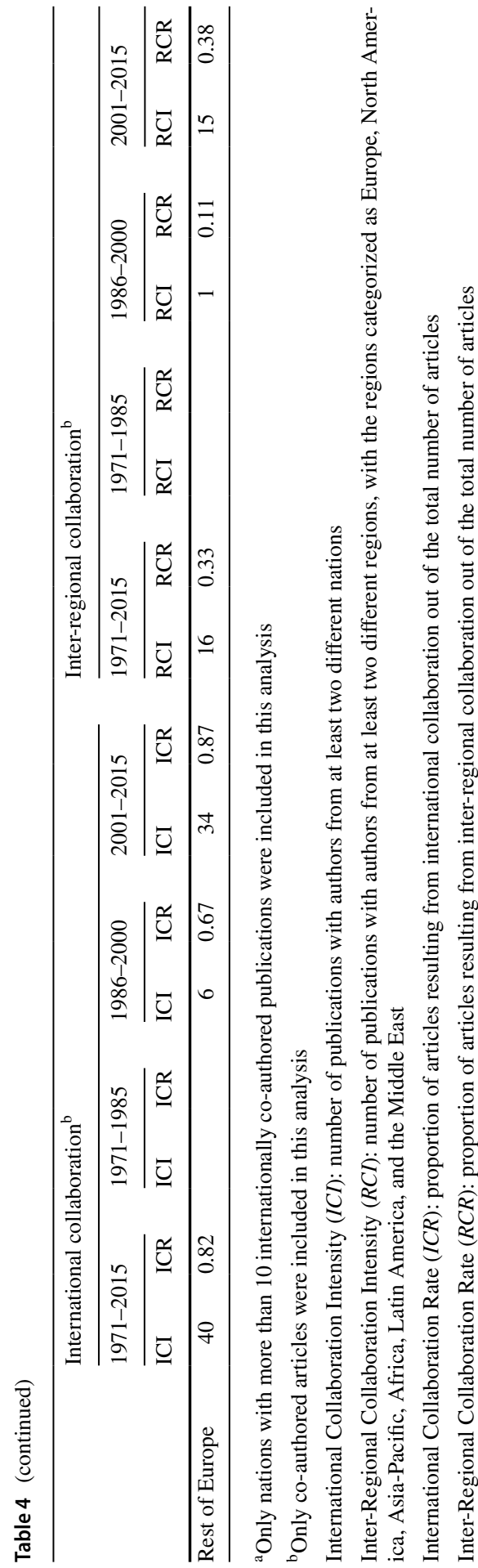



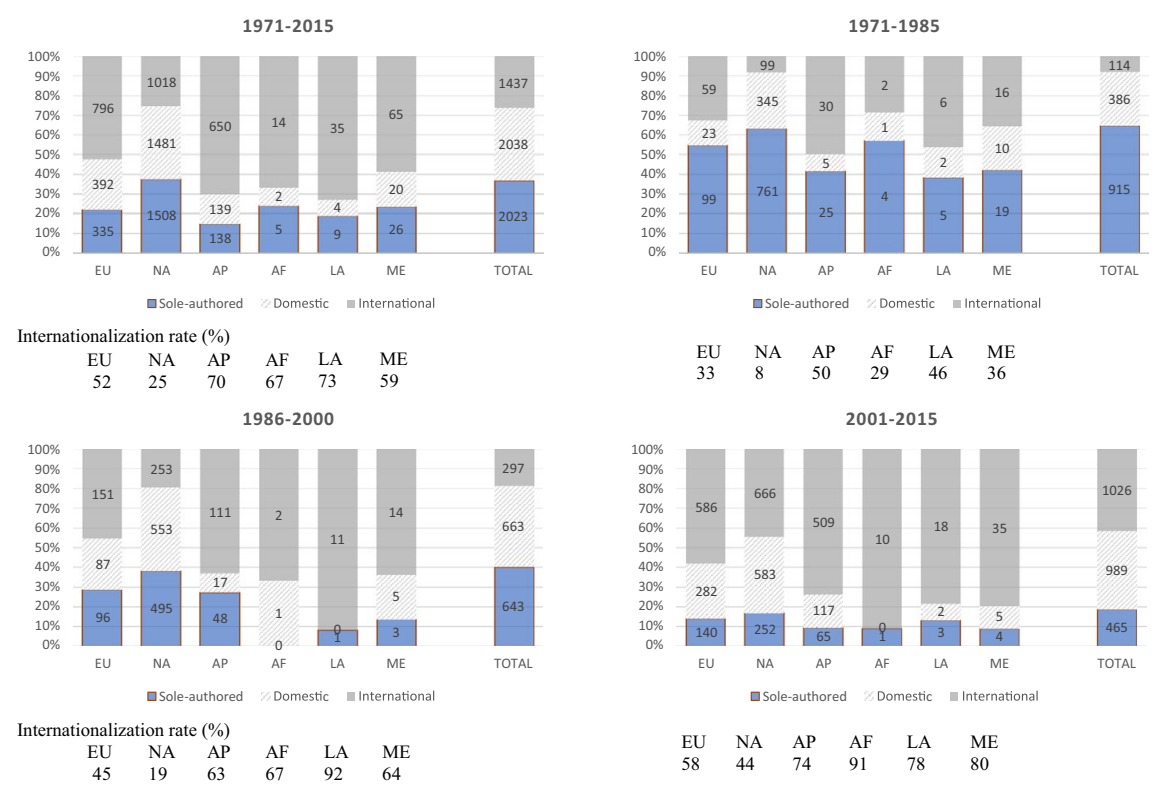

Fig. 2 Distribution of types of publications by region, 1971-2015. EU Europe, NA North America, AP Asia-Pacific, $A F$ Africa, $L A$ Latin America, $M E$ Middle East. Domestic refers to co-authored domestic publications. The percent of international co-authored publications is found by dividing the number of international publications over all publications for each region and period. For instance, the internationalization rate of North America in 1971-1985 is $99 /(99+345+761)=8.21 \%$.

In 2001-2015, half of the authors ranking among the top 15 for Europe also held a spot among the 25 most productive authors globally. For this final period, it is worth noting that the most prolific European authors were trained primarily in the U.K. (7 authors) and North America (5 authors), followed by Sweden and Denmark, with each training 2 leading authors.

\subsection{International Collaboration and European Research Performance}

\subsubsection{Main Trends}

IB research faces a similar trend as in management research in general (Geringer and von Glinow 1999; Kirkman and Law 2005): a decreasing rate of sole-authored publications for all regions (Fig. 2). However, North America remains the region with the highest, albeit decreasing, number of sole-authored publications, which may indicate that its authors are better equipped to publish alone and/or represent a subtle characteristic of the "publish or perish" standard, in that sole-authored papers may be more valued and encouraged for tenure and promotion purposes at U.S. academic 
institutions (Liner and Sewell 2009). Interestingly, the second and third regions in number of sole-authored publications are Europe and Asia-Pacific, respectively, followed by the Middle East, Latin America, and Africa, an order which may reflect resource dependency levels and low penetration of the "publish or perish" standard of the three latter regions.

Indications of resource dependency and penetration of the "publish or perish" standard are further evidenced in data on international collaboration levels. While the proportion of sole-authored articles is decreasing across each of North America, Europe, and Asia-Pacific, examination of the absolute number of soleauthored papers shows a decline for North America, while corresponding figures in Europe and Asia-Pacific evidence an increase over time, albeit with such trends primarily evident only in the final time periods examined. The data for Europe and Asia-Pacific may indicate decreasing resource dependency and increasing adaptation of the sole-author subtlety of the "publish or perish" standard, although evidence supporting such trends should be considered preliminary. In other words, even if North America is gradually moving away from sole-authored papers, the data provide tentative support for Europe's and Asia-Pacific's IB research catching up with North America's performances. In contrast, underrepresented regions of Africa, Latin America, and the Middle East have the highest levels of international collaboration, along with decreasing or stable levels of domestic publications (i.e., publications where all authors are from the same nation), which suggests greater publishing challenges faced by authors in these regions absent the support of co-authors from more established regions. Further, while all regions have intensified their international collaboration, North America's internationalization has increased more rapidly than Europe's and Asia-Pacific's. With growth from $8 \%$ in the first period to $44 \%$ in the last period, North America's internationalization rate has increased by a factor of 5.40, compared to 1.78 for Europe and 1.69 for Asia-Pacific (Fig. 2). These trends suggest a potential shift in the resource dependency relationships between regions, notably as North America increasingly relies on other regions. In contrast, Europe and Asia-Pacific, while still maintaining high levels of international collaboration, are also intensifying their domestic collaboration, though at somewhat modest rates. ${ }^{4}$ For example, between the second and third periods, the rate of domestic publications increased modestly for Europe (from 26\% to 28\%) and a bit more substantively for Asia-Pacific (from 10\% to 17\%), while it decreased for North America (from $43 \%$ to $39 \%$ ).

Similar results are obtained from the ICI and ICR indicators, presented in Table 4, that depict international collaboration for each region and for European nations with more than 10 internationally co-authored publications. In particular, ICI levels are increasing over time for each region, indicating increasing international collaboration. However, results based on the rate of international collaboration (ICR) reveal three distinct, if preliminary, patterns. In the first pattern, North

\footnotetext{
4 As noted by an anonymous reviewer, there may be greater similarity between international collaboration and inter-regional collaboration for North America than may be the case for the European or AsiaPacific regions, where there are many more countries across which collaboration might occur.
} 
America, Africa, and the Middle East exhibit increasing ICR throughout the 45-year period, suggesting that, in these regions, domestic IB research is being replaced by international collaborations. On the other hand, Europe exhibited a decline in ICR in the second period, indicating a rise in domestic IB research, with a subsequent increase in the last period. The third group of regions (Asia-Pacific and Latin America) shows an increase in the second period but a subsequent decrease. Taken together, these results suggest there may be a region-specific threshold of international collaboration that allows regions to develop domestic IB research capabilities conditional on their resources. Europe appears to have achieved this threshold in the second period, while Asia-Pacific and Latin America appeared to have achieved this in the third period. This is consistent with our findings from Tables 1, 2 and 3, where we showed that Europe's upward trend began almost 15 years prior to that of Asia-Pacific. Further, this finding may be indicative that the lower the resources of a region, the higher the level this threshold needs to be in order to support a shift from international to domestic collaboration.

\subsubsection{International and Inter-regional Collaboration, by Region}

Inter-regionalization and internationalization trends provide additional evidence of the centrality of resource dependencies in IB research, along with the dynamic stages of internationalization. Inter-regional collaboration increased dramatically between 1971 and 2015 and reveals important changes in inter-regional relationships. The total number of co-authored publications involving two or more regions (RCI) increased from 95 in 1971-1985 to 237 in the second period to 740 in the last period (Table 4). It is worth noting that these data are highly driven by North America's disproportional share of global IB research production.

In fact, this global trend toward increasing inter-regionalization is unevenly distributed across regions. In addition to holding only a small share of IB publications over 45 years, underrepresented regions had no intra-regional collaboration and very little domestic collaboration (Fig. 2). It may just be that these collaborations exist but do not translate into publications in these primarily U.S.-based journals. On the other hand, while North American authors were expanding their collaboration with authors from other regions (RCR growing from 0.19 to 0.47 between the first and last periods), Europe and Asia-Pacific were turning inward, as indicated by their RCR declining over time. This further confirms our previous findings that dynamic stages of internationalization of IB research may be region-specific (Table 4). These findings on inter-regional collaboration may, of course, be impacted by the larger number of intra-regional nations within both Europe and Asia-Pacific, compared to North America.

Dependency of the underrepresented regions on the more developed regions is even more evident as we consider these inter-regional relationships: underrepresented regions never collaborate with each other, not even through a different region (Table 5). It is only when we include articles with 10 or more authors that these regions find the opportunity to work on the same publication. Similarly, the dominance of North America is clear from these data. Amongst all inter-regionally 
Table 5 Inter-regional collaboration amplitude and main inter-regional partners for European authors, 1971-2015

Europe North America Asia-Pacific Africa Latin America Middle East

$1971-2015$

\begin{tabular}{|c|c|c|c|c|c|c|c|}
\hline & RCA & $\mathrm{RCI}$ & & & & & \\
\hline Europe & 30 & - & $71.3 \%$ & $32.6 \%$ & $0.8 \%$ & $2.3 \%$ & $3.4 \%$ \\
\hline North America & 60 & $49.3 \%$ & - & $48.8 \%$ & $1.1 \%$ & $3.0 \%$ & $5.2 \%$ \\
\hline Asia-Pacific & 26 & $34.1 \%$ & $73.7 \%$ & - & $0.7 \%$ & $0.7 \%$ & $1.2 \%$ \\
\hline Africa & 8 & $35.7 \%$ & $71.4 \%$ & $28.6 \%$ & - & $0.0 \%$ & $0.0 \%$ \\
\hline Latin America & 5 & $40.0 \%$ & $77.1 \%$ & $11.4 \%$ & $0.0 \%$ & - & $0.0 \%$ \\
\hline \multirow{3}{*}{$\begin{array}{l}\text { Middle East } \\
1971-1985\end{array}$} & 18 & $32.3 \%$ & $70.8 \%$ & $10.8 \%$ & $0.0 \%$ & $0.0 \%$ & - \\
\hline & & & & & & & \\
\hline & RCA & $\mathrm{RCI}$ & & & & & \\
\hline Europe & 9 & - & $81.8 \%$ & $16.4 \%$ & $1.8 \%$ & $1.8 \%$ & $3.6 \%$ \\
\hline Partner 1 & & & USA $(69 \%)$ & & & & \\
\hline Partner 2 & & & Canada (16\%) & & & & \\
\hline Partner 3 & & & & Australia (9\%) & & & \\
\hline Partner 4 & & & & Japan (4\%) & & & \\
\hline Partner 5 & & & & & & & Israel (4\%) \\
\hline \multicolumn{8}{|l|}{ 1986-2000 } \\
\hline & RCA & $\mathrm{RCI}$ & & & & & \\
\hline Europe & 11 & - & $87.3 \%$ & $15.9 \%$ & $0.0 \%$ & $2.4 \%$ & $0.8 \%$ \\
\hline Partner 1 & & & USA $(82 \%)$ & & & & \\
\hline Partner 2 & & & & Hong Kong (8\%) & & & \\
\hline Partner 3 & & & Canada $(6 \%)$ & & & & \\
\hline Partner 4 & & & & Australia (3\%) & & & \\
\hline \multicolumn{8}{|l|}{ 2001-2015 } \\
\hline & RCA & $\mathrm{RCI}$ & & & & & \\
\hline Europe & 29 & - & $65.4 \%$ & $39.4 \%$ & $0.9 \%$ & $2.3 \%$ & $4.1 \%$ \\
\hline Partner 1 & & & USA $(56 \%)$ & & & & \\
\hline Partner 2 & & & Canada (12\%) & & & & \\
\hline Partner 3 & & & & Australia (11\%) & & & \\
\hline Partner 4 & & & & China (7\%) & & & \\
\hline Partner 5 & & & & Hong Kong (6\%) & & & \\
\hline
\end{tabular}

Regions: Europe, North America, Asia-Pacific, Africa, Latin America, and the Middle East Inter-regional collaboration amplitude (RCA): number of nations that a region collaborates with Inter-Regional Collaboration Intensity $(R C I)$ : percent of publications with authors from at least two different regions. Given that a publication may have authors from several regions, the percentages for each region (row or column sums) do not add to $100 \%$

The top panel shows the RCA for each region and the RCI among regions for the entire period. The partners for each region are depicted in columns three through eight for the RCI. For instance, Europe collaborated with North America in $71.3 \%$ of their publications over the entire period, but North America collaborated with Europe in $49.3 \%$ of their collaborative publications

The remaining panels show the RCA, RCI, and major partners within each region for Europe in the three periods examined 
co-authored publications, Europe collaborated $71.3 \%$ of the time with North America, akin to Africa (71.4\%) and the Middle East (70.8\%), and this share was even higher for Asia-Pacific (73.7\%) and Latin America (77.1\%). Conversely, when North American authors collaborate with other regions, that only occurred $36 \%$ of the time, far below comparable figures for other regions (see Table 4). Table 5 shows these relationships are much less exclusive (with low shares of collaboration of $1.1 \%$ with Africa, 3.0\% with Latin America, and 5.2\% with the Middle East), and largely favor collaboration with Europe (49.3\%) and Asia-Pacific (48.8\%). These results indicate that regions with high research output tend to collaborate among themselves rather than with the peripheral regions, while the latter regions tend to collaborate with the high research areas rather than with other peripheral regions.

Inter-regional relationships have also strongly evolved, with European authors beginning to show stronger ties with Asia-Pacific. The last period saw a decrease of 22 percentage points in the relationship Europe-North America (from 87.3\% to $65.4 \%$ ), which was compensated for by an increase of 24 percentage points in the relationship Europe-Asia-Pacific. European authors have maintained strong partnerships with the U.S. and Canada, but these have become much less exclusive, declining from $81.8 \%$ to $65.4 \%$ between the first and last periods. In the second period, European authors collaborated more with authors from Hong Kong than they did with Canada. In the last period, they began collaborating more extensively with Chinese authors, thus expanding their relationships with Asia-Pacific authors. ${ }^{5}$

In Europe, the nature of these relationships seems strongly influenced by the U.K., as we will see in more detail in the next sections, confirming the U.K.'s role as an epicenter of IB research in Europe. Specifically, most of these observed relationships correspond with important historical and colonial ties the U.K. shares with Australia, Canada, and Hong Kong. It is not clear whether other European nations leverage their historical ties to expand IB research. While our data do suggest otherwise, it may also be that such collaborations are strong but do not translate into publications in the 14 journals of our study. If such collaborations do actually exist but are not revealed in these journals, this would further reinforce the strong bias toward English-speaking authors and journals, and different ways by which institutions' and authors' research performance are evaluated.

\subsubsection{International and Inter-regional Collaboration by European Nations}

Examination of the most productive European nations reveals a process by which high-performing European nations may have established their leading positions in global IB research. These nations seem to be entering the field first through 'the big door,' i.e., by collaborating intensively with authors from North America. For instance, inter-regional collaboration between Europe and North America increased

\footnotetext{
5 As suggested by an anonymous reviewer, some of the international and inter-regional collaborations reported in this paper can be expected to be impacted by authors collaborating with their former colleagues at their doctoral institutions (including if doctoral students graduate and return to their home nation), or by internationally mobile authors who continue collaborating, for a while at least, with colleagues at their former universities.
} 
from $81.8 \%$ in the first period to $87.3 \%$ in the second period, before dropping to $65.4 \%$ in the last period (Table 5). Similar findings are echoed in the nations panel of Table 4 where, comparing ICI against RCI for the first period, we observe that out of 18 internationally co-authored articles by France in the first period, all but one were inter-regional. During the same period, all internationally co-authored publications for The Netherlands and Sweden were inter-regional, whereas Belgium, Switzerland, Spain, and Norway had no publication that was not the result of interregional collaboration.

During the second step, international collaboration seems more likely to develop within a region, as leading nations in the region may reach a level of resources that renders inter-regional collaboration less essential. Except for The Netherlands and Germany, which were slower than their European peers in their internationalization process, the leading European nations decreased their rate of inter-regional collaboration (RCR) in their second period of publishing in leading journals, even though levels of ICI and RCI increased for nations overall (Table 4). Their leading position and resource endowments may also make leading nations increasingly attractive for other nations in the region. Indeed, during this second step, the ratio of inter-regional (RCI) to international collaboration (ICI) decreased, that is, inter-regional collaboration decreased, but international collaboration increased. We suspect this attractiveness expands to other regions in a third step, as illustrated by the U.K. which, after decreasing its RCR from 0.57 to 0.41 between the first and second period, increased both its RCR and ICR in the last period (i.e., the U.K. increased its global reach, both within and outside Europe).

In other words, these findings suggest a simple model of internationalization of IB research. In the first stage, all nations collaborate with the incumbent leader (North America) to develop the capabilities and/or overcome the barriers of publishing in IB journals. But nations have different resource endowments and absorption capacity, affected by 'gatekeeper ties' (e.g., number of Ph.D.s trained in the U.S.), historical ties, and proficiency in English language, as we saw previously. Of course, cultural differences and other factors may also play a role. This leads to different stages of capability development by region and nation, evidenced by the threshold of internationalization suggested previously.

In the second stage, there is development of a cluster of nations with the highest resource endowments and absorptive capacity that take an increasingly leading role in IB research. In our case, this cluster was Europe and, within this cluster, the U.K. took a leading role in IB publications and training of Ph.D.s. Development of this cluster in the second stage allows nations with less absorptive capacity to collaborate not only with North America but also with the leading nations in the cluster.

This leads to the third stage of IB research evolution, where a third cluster of nations becomes an important player in IB research, namely Asia-Pacific in our study. Asia-Pacific's rise corresponds with increasing international collaboration with not only North America, but also Europe and the U.K. in particular, and thus at this stage the cluster's RCR increases. That is, once a nation develops its domestic capabilities, inter-regional collaboration increases. Of course, our categorization of nations into physical regions may not fully capture nation heterogeneity in or across regions, but we address this issue next. 
France and the U.K., in particular, have been at the forefront of both interregional and international collaboration during all three 15 -year periods, solidifying our previous findings. The U.K. and France were responsible for $42 \%$ and $18 \%$ of the international collaboration and $39 \%$ and $18 \%$ of the inter-regional collaboration for Europe, respectively. This remarkably high concentration of international and inter-regional collaboration by the U.K. and France has not been challenged by a general tendency, for European nations, to increase their ICI and RCI; nor by the increasing number of nations involved in inter-regional collaboration (from 9 in 1971-1985, to 14 and 22 in the second and last periods, respectively) and international collaboration (from 9 in 1971-1985, to 19 and 23 in the second and last periods, respectively).

As indicated above, nations that are the most under-resourced are likely to engage in international collaboration. At the same time, though, because these nations began publishing in the latest periods, they often chose intra-regional over interregional collaboration, as an increasing number of European nations was becoming prominent on the global scene. All but four of these nations are from Eastern Europe, three from the Mediterranean region. They began publishing with a high level of international collaboration (0.67), which kept increasing in the following period (0.87), but their inter-regional collaboration was among the lowest, with an RCR of 0.11 in 1985-2000 and 0.38 in the last period.

\subsubsection{International and Inter-regional Collaboration by Leading European Nations}

In order to shed further light on these trends, we examine the trajectories of the five leading European nations with respect to their international and inter-regional collaboration, namely, the U.K., France, The Netherlands, Germany, and Sweden. We present these detailed analyses in Tables 6, 7, 8, 9 and 10. As shown and discussed below, the data suggest several interesting traits and trends, although the findings should be considered preliminary, due to the small number of cases. Future research may be appropriate to confirm and explore these issues further.

4.4.4.1 The United Kingdom The U.K. had the highest global reach, with an International Collaboration Amplitude of 42. U.K. authors collaborated with 8 nations in the first period, 20 in the second, and 42 in the last, excluding publications with more than 10 authors (Table 6). While the U.S. remained the U.K.'s main partner, the intensity of this relationship dramatically decreased, from $50.0 \%$ in the second period to $32.3 \%$ in the last period. Interestingly, the U.K. seems to have established itself as a dominant actor by leveraging its historical ties with Commonwealth nations. The U.K.'s ICI with Canada and Australia reached a high of $52.4 \%$ in the first period, compared to $28.6 \%$ with the U.S. Further, of the 8 nations the U.K. collaborated with in the first period, only 3 were European. The situation took a radical turn in the second period as the U.K. intensified its relationship with the U.S., with half of the internationally co-authored publications from the U.K. involving a U.S. author. This change was primarily at the expense of the strong relationship the U.K. had with Canada and Australia, which decreased to a low of $11 \%$. 


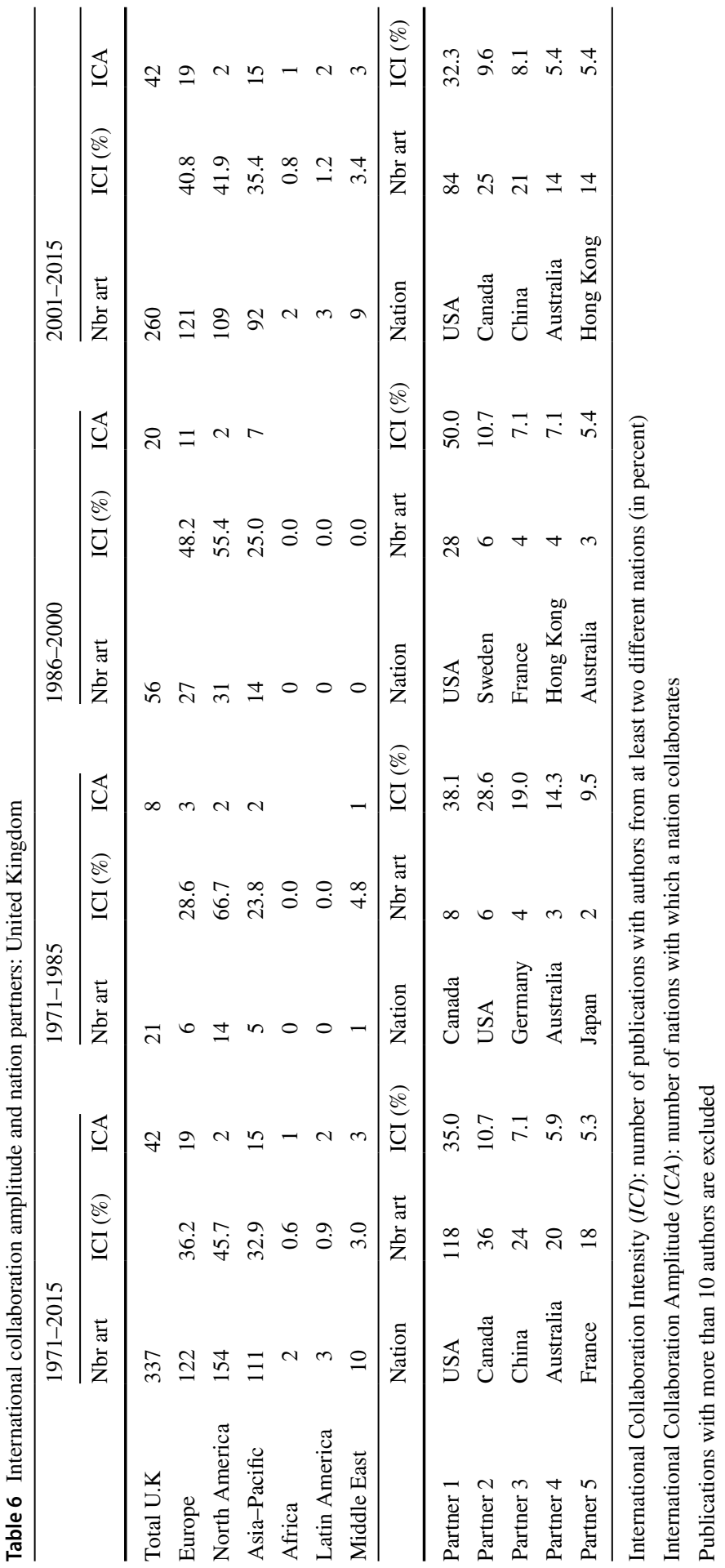




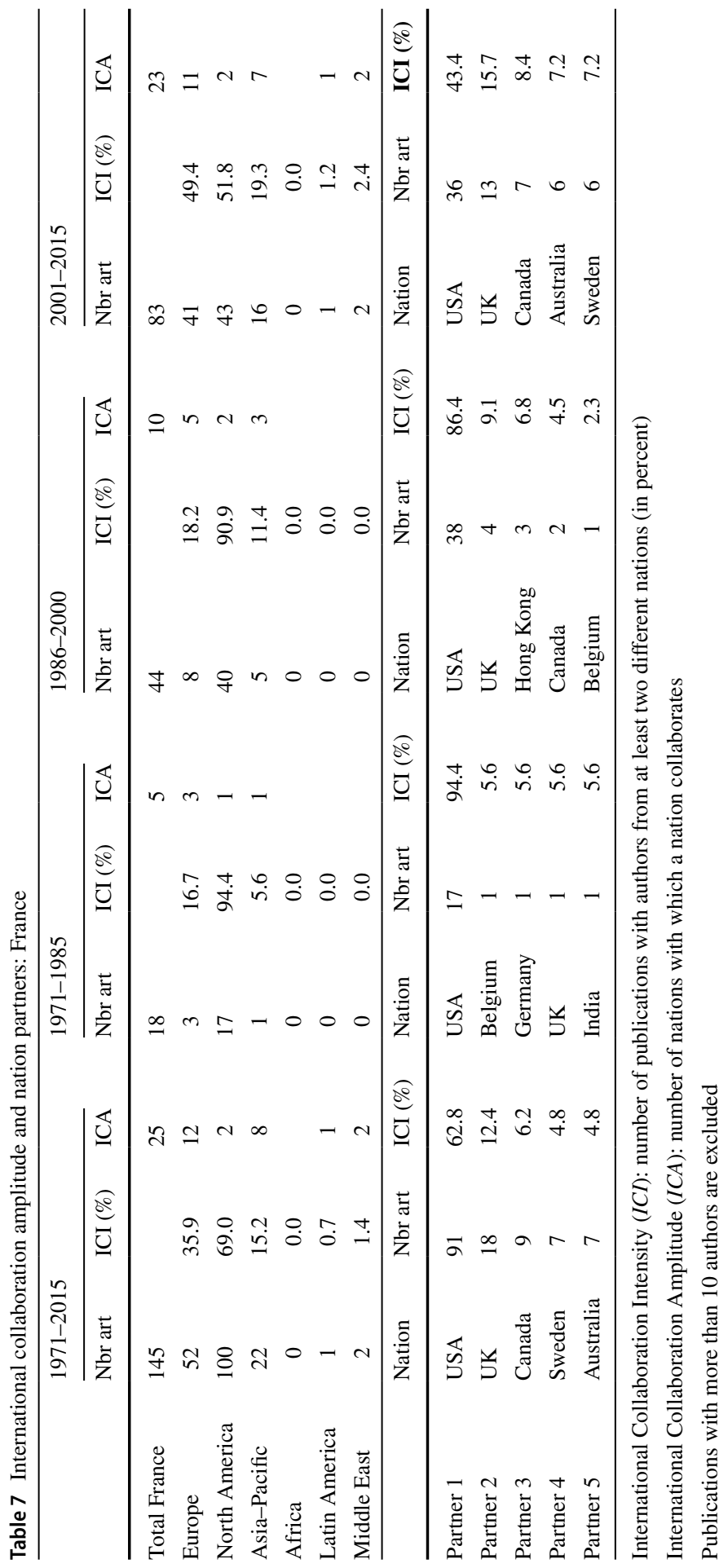




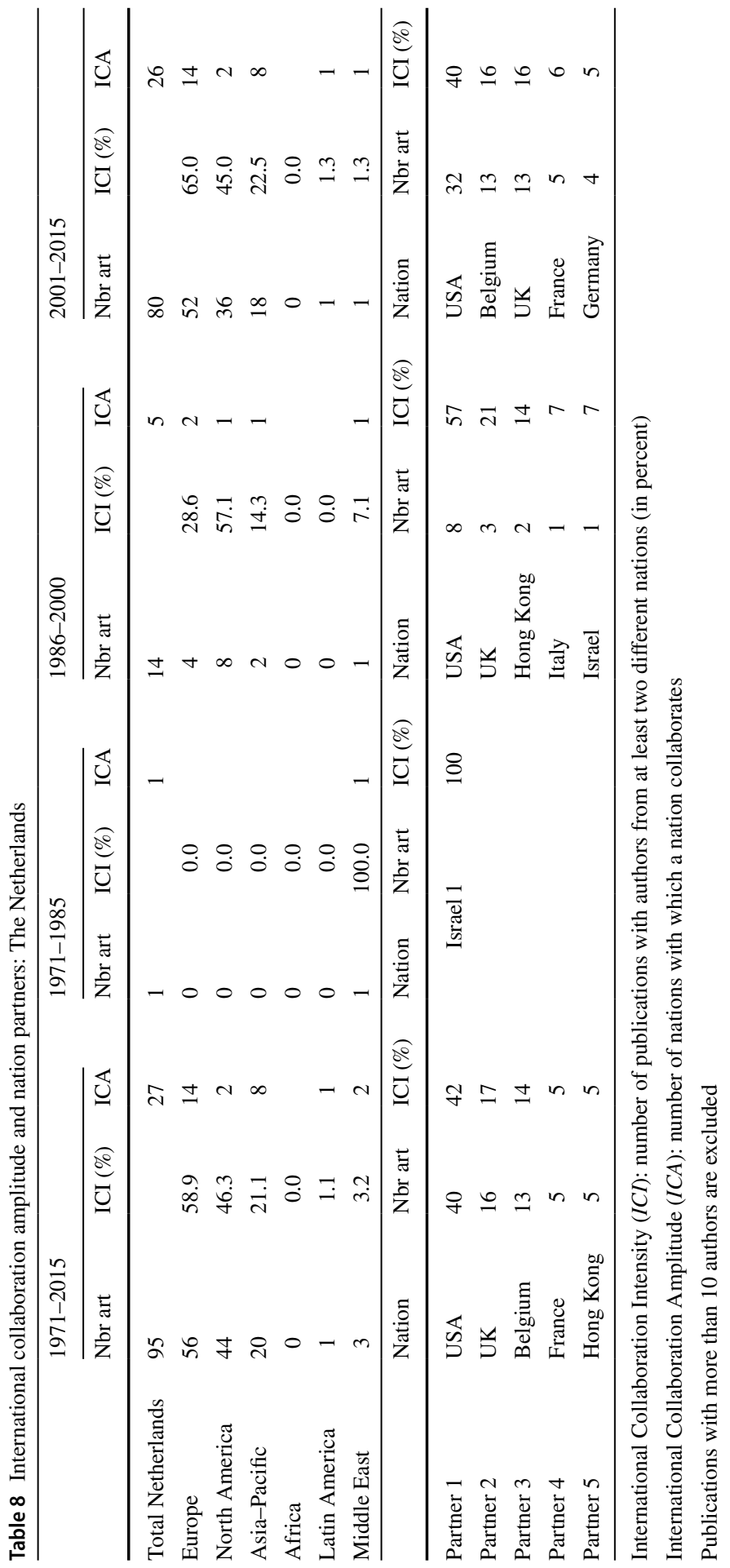




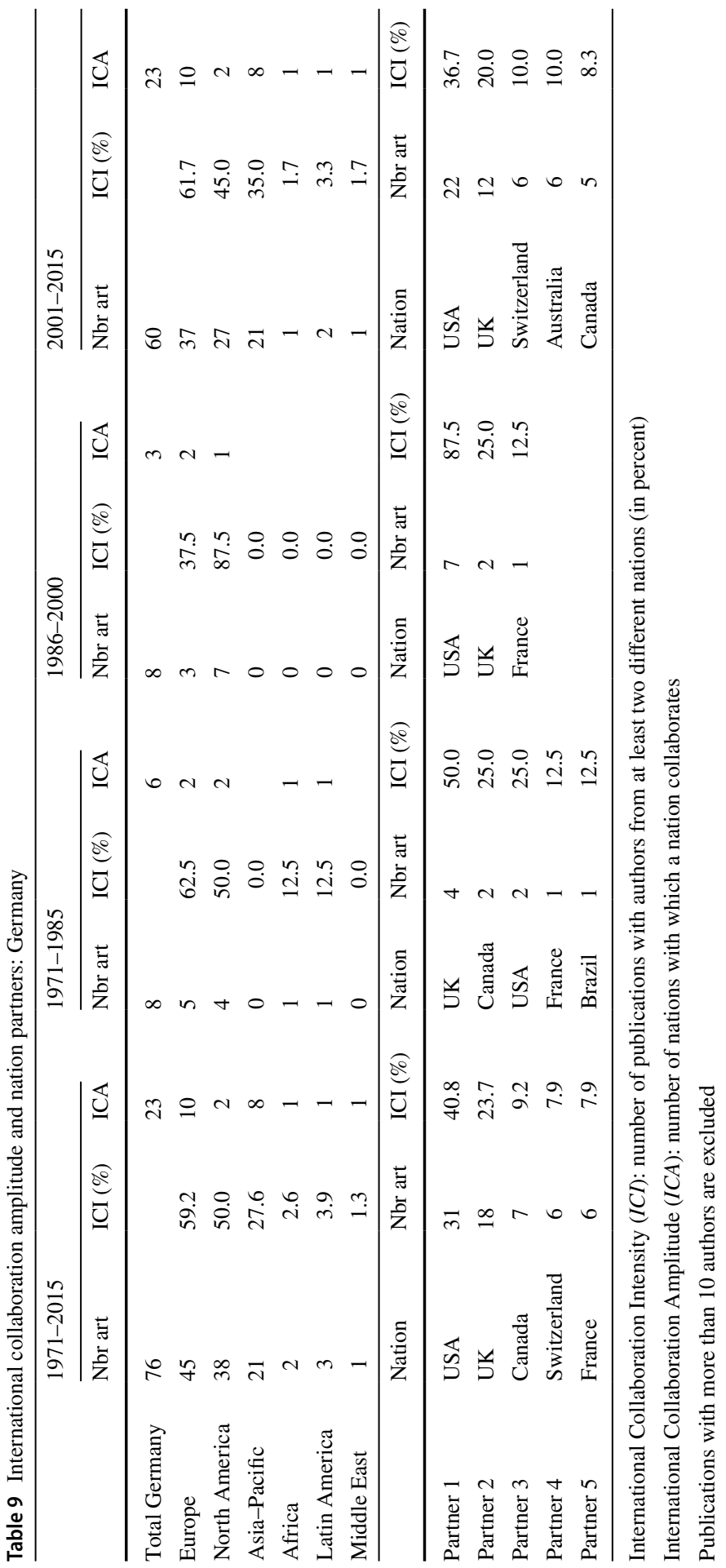




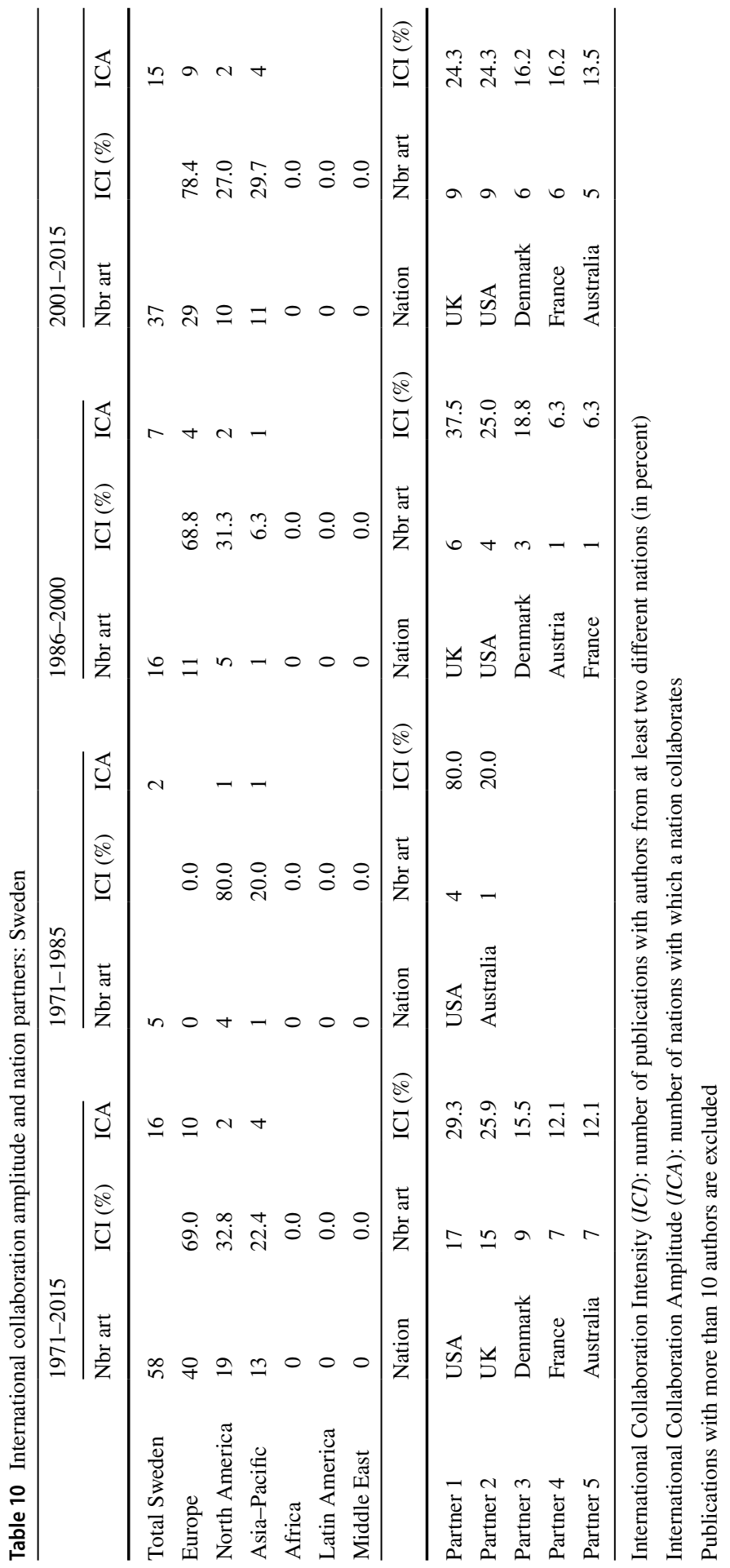


The U.K. also leveraged its increasing global predominance to benefit European nations. At the same time it was surpassing Canada in share of adjusted output (see Table 1), the U.K.'s collaboration with European nations increased from $28.6 \%$ in the first period to $48.2 \%$ in the second period. In the third period, the U.K. stabilized its predominance and continued to expand its network of international partners (42 nations in the last period compared to 20 in the previous period) and extended its global reach by working with authors from all regions. At the same time, other nations' reliance on the U.K. to publish in top journals intensified. Starting in 1986-2000, the U.K. became the second main partner for France (Table 7), The Netherlands (Table 8), and Germany (Table 9), and even replaced the U.S. as first partner for Sweden (Table 10). In the last period, it was the first partner for Sweden and The Netherlands, and second partner for France and Germany.

4.4.4.2 France France held the first rank in both ICR and RCR (0.85 and 0.67, respectively, for the 45-year period), indicating that French authors almost never published without collaboration of a non-French author (Table 4), instead seeking collaboration with authors from English-speaking nations. Indeed, data show that France relied heavily on collaboration with the U.S.: $94.4 \%$ and $86.4 \%$ of internationally co-authored publications in the first and second periods, respectively, involved a U.S. co-author (Table 7). This reliance on English-speaking nations decreased in the third period as France broadened its international reach, both within Europe and with other regions. France collaborated with 5 nations in the first period, 10 in the second, and 23 in the last period.

4.4.4.3 The Netherlands The Netherlands was slower than its European peers in its internationalization process. Despite being the 10th most productive nation in the first period (see Table 1), The Netherlands was also the least likely to collaborate internationally. Further, its internationalization favored European nations more than other regions, as evidenced by the nation's ICR rates growing much faster than its RCR rates (Table 4). Yet, The Netherlands accelerated its Europeanization more than any other European nation. Between the first and second periods, its share of internationally co-authored articles involving European nations increased from $28.6 \%$ to $65 \%$. During the same period, The Netherlands decreased its relationship with North America by 12 percentage points and intensified its relationship with Asia-Pacific by 8 points. We note the same tendency as France to partner with a nation with English proficiency. Collaboration with the U.S., the U.K., Canada, Australia, Singapore, and Hong Kong amounted to $70 \%$ of The Netherlands' publications in the last period (Table 8).

4.4.4.4 Germany Germany experienced a different trajectory than the other leading European nations. While Germany had one of the most diverse sets of partners in the first period, including some collaboration with Africa and Latin America, its ICA decreased from 6 to 3 in the second period when $87.5 \%$ of the articles were published in collaboration with the U.S. (Table 9). In the last period, though, Germany accelerated both its internationalization intensity and global reach, becom- 
ing one of the rare European nations to collaborate with nations from all regions. This happened primarily at the expense of its collaboration with the U.S. which, even though it remained its first partner, decreased to $36.7 \%$. Collaboration with English-speaking nations was also dominant during that period.

4.4.4.5 Sweden Sweden remained relatively stable, both in its share of IB research productivity (Table 4) and its international and inter-regional collaboration measures. Despite its position as a leading producer of IB research, Sweden stands out for its relatively low international collaboration levels (Table 4) and its limited global reach, with a maximum of 15 collaborating nations in the last period (Table 10). Further, contrary to the other nations sampled in this analysis, Sweden did not collaborate at all with underrepresented regions, instead limiting its collaboration to European nations, primarily from northern Europe, with a total share of $78.4 \%$.

\section{Discussion and Future Research}

We introduced this work by suggesting the need to assess the role of European nations, institutions, and authors in the development of IB research. Despite a central role in IB knowledge production and dissemination, limited prior assessment of Europe's contribution to the field left many questions unaddressed. For instance, what are potential constraints for European academic institutions and authors as they seek to be recognized as leading global actors in the field? What is the role of international collaboration in overcoming such constraints? More generally, we were interested in understanding how European IB research evolved within a context of globalization of academic practices such as "publish or perish" (Miller et al. 2011) or the use of journal publications as a measure of research performance (Aïssaoui and Geringer 2018; Geringer and von Glinow 1999; Lahiri and Kumar 2012; Ryazanova et al. 2017).

As our study examined the evolution of IB research over 45 years, 76 nations, 14 journals, 5508 publications, 5853 authors, and 1542 institutions, we are able to shed light on these questions and identify important trends. Our findings provide a salient overview of the state and evolution of the field of IB as they build on the same data, methods, and concept definitions, thus allowing a strong foundation for comparability and identification of trends and patterns within and across nations and regions. Findings from the evolution of Europe's role in IB research allow us to proffer several novel contributions and to identify practical implications for academia.

\subsection{International Collaboration and Global Visibility}

International collaboration has been widely associated with improved creativity and thus research performance (Ryazanova et al. 2017), specifically because of 
the possibility to leverage the diversity of collaborating authors' theoretical and methodological perspectives (Abramo et al. 2018; Burt 1992). Our findings suggest a positive relationship between international collaboration and research performance, measured as publications in top journals, at least within IB scholarship.

Building on Abramo et al.'s (2018) distinction between international collaboration intensity (i.e., a nation's level of international collaboration) and international collaboration amplitude (i.e., a nation's number of foreign partners), we developed a detailed analysis of the leading European nations with IB publications in 14 journals. Using this approach, our findings suggest such international collaboration efforts best support research performance and global visibility when they focus both on intensity and amplitude. For instance, The Netherlands' and Germany's rankings improved with increased international collaboration and amplitude. Conversely, Sweden's slower internationalization and collaboration with a narrower set of nations and regions has been accompanied by a decline in its global ranking.

This evaluation has direct implications at the levels of academic institutions, nations, and regions, notably by guiding institutions' decision-making on their investments in international collaboration, including decisions on hiring of internationally mobile scholars who might have existing networks of collaborators. Indeed, if the initial findings presented in our study regarding the role and/or combination of each type of international collaboration on research performance are confirmed by future research, both within IB and within the broader area of management as a whole and perhaps across business disciplines in general, institutions, nations, and regions will be better equipped to gauge the international collaboration intensity and amplitude needed to achieve their goals. Thus, we expand on the widespread argument that international collaboration positively impacts research performance (Leonidou et al. 2010; Ryazanova et al. 2017) by suggesting that various types of international collaboration may have different impacts. We further identified a processual pattern of international collaboration, shedding further light on the role that resource dependencies may play in the evolution of the field.

\subsection{Resource Dependencies and Global IB Research Performance}

Resources, such as access to valuable and often costly data (Eden and Rynes 2003), connections to editors and gatekeepers (Brogaard et al. 2014; Colussi 2018; Harzing and Metz 2013; Zinovyeva and Bagues 2015), and English proficiency (Horn 2017; Lillis and Curry 2010; Ryazanova et al. 2017), have been identified as important conditions, and by extension barriers, to publishing in leading journals. Additional constraints, specifically for non-North American authors, include lack of familiarity and expertise with the theoretical and methodological approaches favored by North American research (Lopez-Navarro et al. 2015). Our findings are consistent with the existence of such constraints, but also point to patterns of resource dependencies between regions and nations seeking to contribute to IB research.

First, we identified a processual pattern which indicates that in order for a nation to gain visibility in leading IB journals, it often requires initial collaboration with 
North American authors. We found no nation that was able to gain a prominent position without first collaborating with North America, and all regions collaborated with North America on at least $70.8 \%$ of all co-authored articles, with a high of 77.1\% observed for Latin America (Table 5). In a second step, after a nation has become more established, its collaboration with North America begins to decline and is replaced with domestic and/or intra-regional collaboration. The third step of this pattern is when the nation becomes sufficiently established and resourced to attract authors from a broader range of nations and regions. This three-step process was observed in all five leading European nationns (Tables 6, 7, 8, 9, 10).

This finding is consistent with previous research linking resource dependencies to international collaboration by the least economically developed nations (ChinchillaRodriguez et al. 2018). Ribeiro et al. (2018: 165) further suggest that these resource dependencies may vary depending on the development stage of a nation, noting that, "the least developed countries depend strongly on international cooperation to start". Our study suggests this assessment may be underestimated. While there is strong evidence of such a link, we also find that the least developed regions never collaborate with each other, except where the research involves a very large number of co-authors.

Importantly, the patterns of resource dependencies and the three-step process we identified apply to developed and less developed nations equally, which further suggests that while economic resources are central, they are not sufficient to support a nation's research productivity and global visibility. Instead, English proficiency stands as a critical resource which, when lacking, may further aggravate this economic disadvantage. While European nations' reliance on the U.S. has decreased substantially, it has often been replaced by increasing reliance on the U.K. In addition, out of the 18 leading European authors, 12 were trained in either the U.K. or the U.S. In fact, the criticality of English proficiency probably partly explains the U.K.'s emergence as the epicenter of IB research in Europe. Data also suggest that Hong Kong may be assuming a similar role in Asia-Pacific and, in doing so, contributing to further international diversification associated with publishing IB research in journals such as those studied in this paper, albeit with English language ability as a key element in its emergence.

This reliance on developed and English-speaking nations has implications for development of the field. First, it may hinder in-depth comparative research among emerging nations, notably research capable of identifying universals without sacrificing the role of emics in explaining business phenomena (Leung 2009, 2012; Tsui 2007). This reliance is unfortunate, given that cross-national comparative research is a central part of the discipline (Ricks 1985). This reliance is of further concern because emerging nations are also likely to be the most dynamic with respect to their economic, political, and social environments (Peng 2002), which warrants a keen understanding of these dynamics to better evaluate their impact on IB research.

Progress with respect to comparative approaches has been made recently, as reflected in research such as the GLOBE project (House et al. 2004) or X-Culture (Taras et al. 2012) that build on collaboration among a large set of nations and regions. For instance, GLOBE's investigation aims at discriminating the universals from the emics in leadership phenomena. There is, however, room to further expand 
such efforts, notably with research examining the impact of different theoretical perspectives or different foci on our understanding of business phenomena (Bajwa and Konig 2019; Eden and Rynes 2003; Hofstede 1981).

Mangematin and Baden-Fuller (2008) explained that such advancements would require establishment of research epicenters outside North America. The U.K. has taken on this role, evidenced not only by European nations' increasing collaboration with the U.K. but also their increasing collaboration with nations sharing historical connections to the U.K. (e.g., Commonwealth nations). There is potential to further leverage historical ties that other European nations share with other nations or regions, notably in the underrepresented regions of Africa, Latin America, Asia, and the Middle East.

Academic conferences such as the Academy of International Business or the Academy of Management (AOM) annual meetings have recently promoted higher involvement from underrepresented regions. For instance, the AOM developed a group to foster research from and with African researchers, investing in not only marketing efforts but also travel funds to encourage higher visibility of African research. European nations are in a prime position to replicate such initiatives, notably as the EU encourages and financially supports international collaboration in education and academia (EU Education 2020). Recent emergence or expansion in virtual conferences and webinars, including as a result of COVID-19, may further facilitate international cooperation with and capacity-building in underrepresented regions, particularly to the extent that such virtual environments are sustained over time and effectively assist in overcoming resource constraints such as travel-related expenses and logistics.

\subsection{Limitations and Implications for Future Research}

All studies have limitations and our research is no exception. Our study perpetuates the common methodological limitation raised by Ryazanova et al. (2017), in that measures used to assess research performance-in this case publications in 14 leading journals - fail to recognize the variety of national systems of research evaluation (Saunders et al. 2011). Further, while there is evidence of an Americanization of academic practices such as "publish or perish," even when these practices are adopted by European nations and their institutions, it is often after significant adaptations. Thus, it is worth repeating Ryazanova et al.'s (2017, p. 832) assertion that, "A signal should closely reflect the underlying unobservable quality for which it serves as a proxy".

In addition, small numbers of observations for some of the analyses in this study suggest that some of the results may be viewed as only preliminary. Future research could address these issues by developing regional assessments and by developing a larger sampling of the population, perhaps by further broadening the list of publication outlets that are examined or by broadening the focus, perhaps to the entire field of management or even a range of different fields of business (e.g., marketing, finance, accounting). Such an approach might provide insight into whether the patterns discovered in this study are mirrored in or differ across other academic fields. 
This study also examined research productivity based on the country of institutional affiliation for the authors. Future research might add data based on the birth nation of authors or their nationality at the time of publication, to the extent that these differ. Future research might also examine the impact of individual authors, as mobile individual academics might impact the relative performance of institutions and their countries. Such research might also examine strategies of institutions, in terms of recruiting, hiring, incentivizing, and providing support to academics in order to influence the absolute or relative level of publication performance and ranking versus peer institutions.

Future research could also take a more qualitative approach to bibliometric analyses, such as Mangematin and Baden-Fuller (2008), to verify the decreased dependency on North American research. It is not clear from our data whether the decreasing predominance of North American research has enhanced introduction of a wider range of theoretical and methodological approaches, or whether, as suggested by Mangematin and Baden-Fuller (2008), it is a result of the diffusion of North American research practices to other regions.

Examinations of national institutional performance, such as our study examining research productivity in IB, inevitably embody limitations due to the conceptual and practical choices that must be addressed in their design and execution. Nevertheless, our study helps to advance understanding of this phenomenon. Using 45 years' worth of data from 14 prominent journals, this study makes several novel contributions to the field, including identification of a unique internationalization process of IB research that consists of three distinct stages driven by international collaboration; demonstrating the role of international collaborations in helping to overcome publication barriers at the regional and country level; and highlighting the role of both scale and scope of international collaborations in achieving a top-ranked position globally. We hope these discoveries can foster additional discussion and research to help further increase our understanding of how to foster better quantity and quality of research in IB.

Acknowledgements The authors would like to thank the anonymous reviewers and the editors of this journal for their constructive comments and support during the review process. The authors also acknowledge support provided by the Research Seed Grant program of Ohio University's College of Business.

Author Contributions All authors contributed equally to this study; author order is alphabetical by surname.

Code Availability SAS code available upon request from the corresponding author.

\section{Appendix: Definition of International Business Research}

International business research is defined by Nehrt et al. (1970), and repeated by Ricks (1985, p. 1), as:

"scholarly investigation and/or analysis of a subject that meets the following criteria: 
1. It is concerned with firm-level business activity that crosses national boundaries or is conducted in a location other than the firm's home country. (This activity may be the movement of goods, capital, people, and know-how, or it may be manufacturing, extraction, construction, banking, shipping, advertising, and the like.)

2. It is concerned with the interrelationship between the operations of the business firm and international or foreign environments in which the firm operates.

3. It does not include studies devoted to economic development, development planning, foreign trade, and the international monetary system, which belong to development and international economics. Excluded also are studies of foreign legal, political, economic, and social environments. These belong to the fields of law, political science, economics, and behavioral science unless the study itself relates the environment directly to the organizational, operational, or decision-making problems of international business firms.

4. It does not include studies of business activities in given foreign nations. A study of marketing channels in Turkey, whether it is done by a U.S., French, or Turkish professor of marketing, is still a study about domestic business in Turkey. This would not be international business any more than would the study of motivation levels of Portuguese workers or the study of personal income distribution in Japan, even though each may be of interest to international business firms.

5. As an exception to point 4 , however, comparative business studies are included within this definition. For example, a study of pharmaceutical marketing channels in Germany, Italy, Brazil, and Japan, which makes comparisons and analyzes the causes and effects of similarities and differences, would be considered international business research even though it was not concerned with the relationship between the marketing channels within each country and international business firms".

\section{References}

Abramo, G., D’Angelo, C. A., \& Di Costa, F. (2019). The collaboration behavior of top scientists. Scientometrics, 118(1), 215-232.

Abramo, G., D’Angelo, C. A., \& Solazzi, M. (2018). Are researchers that collaborate more at the international level top performers? An investigation on the Italian university system. Working paper.

Adler, N. J., \& Harzing, A. W. (2009). When knowledge wins: Transcending the sense and nonsense of academic rankings. The Academy of Management Learning \& Education, 8(1), 72-95.

Aïssaoui, R., \& Geringer, M. J. (2018). International business research output and rankings of AsiaPacific universities: A 40-year time-series analysis. Asia Pacific Journal of Management, 35, 993-1023.

Aithal, S. (2016). Study on research productivity in world top business schools. MRPA Paper, No. 72246. https://mpra.ub.uni-muenchen.de/72246/.

Amis, J. M., \& Silk, M. L. (2008). The philosophy and politics of quality in qualitative organizational research. Organizational Research Methods, 11(3), 456-480.

Bajwa, N. H., \& Konig, C. J. (2019). How much research in the top journals of industrial/organizational psychology dominated by authors from the US? Scientometrics, 120(3), 1147-1161. 
Baruch, Y. (2001). Global or North American? A geographic based comparative analysis of publications in top management journals. International Journal of Cross Cultural Management, 1(1), 109-126.

Bedeian, A. G., Taylor, S. G., \& Miller, A. N. (2010). Management science on the credibility bubble: Cardinal sins and various misdemeanors. Academy of Management Learning and Education, 9(4), 715-725.

Bird, S. J. (2006). Research ethics, research integrity and the responsible conduct of research. Science and Engineering Ethics, 12(3), 411-412.

Brogaard, J., Engelberg, J., \& Parsons, C. A. (2014). Networks and productivity: Causal evidence from editor rotations. Journal of Financial Economics, 111(1), 251-270.

Burgess, S., Gea-Valor, M. L., Moreno, A. I., \& Rey-Rocha, J. (2014). Affordances and constraints on research publications: A comparative study of the language choices of Spanish historians and psychologists. Journal of English for Academic Purposes, 14, 72-83.

Burt, R. S. (1992). Structural holes: The social structure of competition. Cambridge: Harvard University.

Chan, K. C., Fung, H.-G., \& Leung, W. K. (2006). International business research: Trends and school rankings. International Business Review, 15(4), 317-338.

Chinchilla-Rodriguez, Z., Miao, L., Murray, D., Robinson-Garcia, N., Costas, R., \& Sugimoto, C. R. (2018). A global comparison of scientific mobility and collaboration according to national scientific capacities. Frontiers in Research Metrics and Analytics, 3(17), 1-14.

Cohen, L. M., Morgan, R. D., DiLillo, D., \& Flores, L. Y. (2003). Why was my major professor so busy? Establishing an academic career while pursing applied work. Professional Psychology Research and Practice, 34(1), 88-94.

Colussi, T. (2018). Social ties in academia: A fried is a treasure. Review of Economics and Statistics, $100(1), 45-50$.

Creswell, J. W. (2009). Research design: Qualitative, quantitative, and mixed methods approaches (3rd ed.). Thousand Oaks: Sage Publications.

de Rond, M., \& Miller, A. N. (2010). Publish or perish: Bane or boon of academic life? Journal of Management Inquiry, 14(4), 321-329.

Doktor, R., Tung, R. L., \& von Glinow, M. A. (1991). Incorporating international and intercultural management research: What's next? Academy of Management Review, 16(2), 362-365.

Earley, P. C., \& Singh, H. (1995). International and intercultural management research: What's next? Academy of Management Journal, 38(2), 327-340.

Eden, D., \& Rynes, S. (2003). Publishing across borders: Furthering the internationalization of AMJ. Academy of Management Journal, 46(6), 679-683.

EU Education. (2020). European Commission policy on educational issues. https://ec.europa.eu/info/ education/policy-educational-issues_en.

Ellis, P. D., \& Zhan, G. (2011). How international are the international business journals. International Business Review, 20(1), 100-112.

Engwall, L. (1996). The Vikings versus the world: An examination of Nordic business research. Scandinavian Journal of Management, 12(4), 425-437.

Engwall, L. (2004). The Americanization of Nordic management education. Journal of Management Inquiry, 13(2), 109-117.

Enever, J. (2012). Current policy issues in early foreign language learning. Center for Educational Policy Studies Journal, 2(3), 9-26.

Flowerdew, J. (2008). Scholarly writers who use English as an additional language: What can Goffman's "Stigma" tell us? Journal of English for Academic Purposes, 7(2), 77-86.

Geringer, J. M., \& von Glinow, M. A. (1999). The development of the field of international business: An examination of MIR under Klaus Macharzina's editorial leadership. Management International Review, 39(2), 5-25.

Glick, W. H., Miller, C. C., \& Cardinal, L. B. (2007). Making a life in the field of organization science. Journal of Organizational Behavior, 28(7), 817-835.

Goerke, L., \& Holler, M. J. (1998). Strategic standardizatin in Europe: A public choice perspective. European Journal of Law and Economics, 6(2), 95-112.

Hall, C. M. (2001). Publish and perish? Bibliometric analysis, journal ranking and the assessment of research quality in tourism. Tourism Management, 32(1), 16-27.

Harzing, A. W., \& Metz, I. (2012). Explaining geographic diversity of editorial boards: The role of conference participation and English language skills. European Journal of International Management, 6(6), 697-715.

Harzing, A. W., \& Metz, I. (2013). Practicing what we preach: The geographic diversity of editorial boards. Management International Review, 53(2), 168-187. 
Hewitt-Dundas, N. (2012). Research intensity and knowledge transfer activity in UK universities. Research Policy, 41(2), 262-275.

Hicks, D. (2012). Performance-based university research funding systems. Research Policy, 41(2), 251-261.

Hofstede, G. (1981). Culture and organizations. International Studies of management and organization, $10(4), 15-41$.

Horn, S. A. (2017). Non-English nativeness as stigma in academic settings. Academy of Management Learning and Education, 16(4), 579-602.

House, R. J., Hanges, P. J., Javidan, M., Dorfman, P. W., \& Gupta, V. (2004). Leadership, culture, and organizations: The GLOBE study of 62 societies. Thousand Oaks: Sage Publications.

Jarley, P., Chandler, T. D., \& Faulk, L. H. (1998). Are we playing the same game? Publishing task environment and research productivity among management specialists. Human Relations, 51(6), 799-824.

Jonkers, K., \& Cruz-Castro, L. (2013). Research upon return: The effect of international mobility on scientific ties, production and impact. Research Policy, 42(8), 1366-1377.

Kieser, A. (2004). The Americanization of academic management education in Germany. Journal of Management Inquiry, 13(2), 90-97.

Kipping, M., Üsdiken, B., \& Puig, N. (2004). Imitation, tension, and hybridization: Multiple "Americanizations" of management education in Mediterranean Europe. Journal of Management Inquiry, 13(2), 98-108.

Kirkman, B., \& Law, K. (2005). International management research in AMJ: Our past, present, and future. Academy of Management Journal, 48(2), 377-386.

Kostova, T. (1997). Country institutional profile: Concept and measurement. Proceedings of the Academy of Management, 1, 180-184.

Kostova, T. (1999). Transnational transfer of strategic organizational practices: A contextual perspective. Academy of Management Review, 24(2), 308-324.

Kothari, T., \& Lahiri, S. (2012). Yesterday, today and tomorrow: An overview of research publications in the Journal of International Management. Journal of International Management, 18(1), 102-110.

Lages, C. R., Pfajfar, G., \& Shohan, A. (2015). Challenges in conducting and publishing research on the Middle East and Africa in leading journals. International Marketing Review, 32(1), 52-77.

Lahiri, S., \& Kumar, V. (2012). Ranking international business institutions and faculty members using research publication as the measure. Management International Review, 52(3), 317-340.

Leonidou, L. C., Katsikeas, C. S., \& Coudounaris, D. N. (2010). Five decades of business research into exporting: A bibliographic analysis. Journal of International Management, 16(1), 78-91.

Leung, K. (2009). Never the Twain shall meet? Integrating Chinese and Western management research. Management and Organization Review, 5(1), 121-129.

Leung, K. (2012). Indigenous Chinese management research: Like it or not, we need it. Management and Organization Review, 8(1), 1-5.

Lillis, T., \& Curry, M. (2010). Academic writing in a global context. Abington: Routledge.

Liner, G. H., \& Sewell, E. (2009). Research requirements for promotion and tenure at PhD granting departments of economics. Applied Economics Letters, 16(8), 765-768.

Lopez-Navarro, I., Moreno, A. I., Quitanilla, M. A., \& Rey-Rocha, J. (2015). Why do I publish research articles in English instead of my own language? Differences in Spanish researchers' motivations across scientific domains. Scientometrics, 103(3), 939-976.

Mangematin, V., \& Baden-Fuller, C. (2008). Global contests in the production of business knowledge: Regional centres and individual business schools. Long Range Planning, 41(1), 117-139.

March, J. G. (2005). Parochialism in the evolution of a research community: The case of organization studies. Management and Organization Review, 1(1), 5-22.

Meyer, K. E. (2006). Asian management research needs more self-confidence. Asia Pacific Journal of Management, 23, 119-137.

Miller, A. N., Taylor, S. G., \& Bedeian, A. G. (2011). Publish or perish: Academic life as management faculty live it. Career Development International, 16(5), 422-445.

Minkov, M., \& Hofstede, G. (2011). The evolution of Hofstede's doctrine. Cross Cultural Management: An International Journal, 18(1), 10-20.

Modiano, M. (2017). English in a post-Brexit European Union. World Englishes, 36(3), 313-327.

Morrison, A. J., \& Inkpen, A. C. (1991). An analysis of significant contributions to the international business literature. Journal of International Business Studies, 22(1), 143-153.

Nehrt, L. C., Truitt, J. F., \& Wright, R. W. (1970). International business research: Past, present, and future. Bloomington: Indiana University Graduate School of Business. 
Peng, M. W. (2002). Towards an institution-based view of business strategy. Asia-Pacific Journal of Management, 19, 251-267.

Piocuda, J. E., Smyers, J. O., Knyshev, E., Harris, R. J., \& Rai, M. (2015). Trends in internationalization and collaboration in US psychology journals, 1950-2010. Archives of Scientific Psychology, 3(1), 82-92.

Ribeiro, L. C., Rapini, M. S., Alves Silva, L., \& Alburquerque, E. M. (2018). Growth patterns of the network of international collaboration in science. Scientometrics, 114(1), 159-179.

Ricks, D. A. (1985). International business research: Past, present, and future. Journal of International Business Studies, 16(2), 1-4.

Robertson, R. (1997). Comments on the "global triad" and "glocalization." In N. Inoue (Ed.), Globalization and indigenous culture (pp. 217-225). Tokyo: Shinshokan.

Ryazanova, O., McNamara, P., \& Aguinis, H. (2017). Research performance as a quality signal in international labor markets: Visibility of business schools worldwide through a global research performance system. Journal of World Business, 52(6), 831-841.

Sahlin, K., \& Weldin, L., et al. (2008). Circulating ideas: Imitation, translation and editing. In R. Greenwood (Ed.), The SAGE handbook of organizational institutionalism (pp. 218-242). London: Sage Publications.

Saunders, J., Wong, V., \& Saunders, C. (2011). The research evaluation and globalization of business research. British Journal of Management, 22(3), 401-419.

Scherer, R. F., Javalgi, R. G., \& Bryant, M. (2005). Challenges of AACSB international accreditation for business schools in the United States and Europe. Thunderbird International Business Review, 47(6), 651-669.

Settles, I. H., Cortina, L. M., Malley, J., \& Stewart, A. J. (2006). The climate for women in academic science: The good, the bad, and the changeable. Psychology of Women Quarterly, 30(1), 47-58.

Taras, V., Bryla, P., Forquer, S., Jimenez, A., Minor, M., Muth, T., et al. (2012). Changing the face of international business education: The X-Culture Project. AIB Insights, 12(4), 11-17.

Tiratsoo, N. (2004). The "Americanization" of management education in Britain. Journal of Management Inquiry, 13(2), 118-126.

Treviño, L., Mixon, F., Funk, C., \& Inkpen, A. (2010). A perspective on the state of the field: International business publications in the elite journals as a measure of institutional and faculty productivity. International Business Review, 19(4), 378-387.

Tsui, A. S. (2007). From homogeneization to pluralism: International management research in the academy and beyond. Academy of Management Journal, 50(6), 1353-1364.

Tuselmann, H., Sinkovics, R. R., \& Pishchulov, G. (2016). Revisiting the standing of international business journals in the competitive landscape. Journal of World Business, 51(4), 487-498.

Üsdiken, B. (2004). Americanization of European management education in historical and comparative perspective. Journal of Management Inquiry, 13(2), 87-89.

Üsdiken, B. (2014). Centres and peripheries: Research styles and publication patterns in 'top' US journals and their European alternatives, 1960-2010. Journal of Management Studies, 51(5), 764-789.

Viiu, G. A., Paunescu, M., \& Miroiu, A. (2016). Research-driven classification and ranking in higher education: An empirical appraisal of a Romanian policy experience. Scientometrics, 107(2), 785-805.

Wilson, L. (1942). The academic man: A study in the sociology of a profession. New York: Oxford University Press.

Xu, N., Poon, W. P. H., \& Chan, K. C. (2014). Contributing institutions and authors in international business research: A quality-based assessment. Management International Review, 54(5), 735-755.

Yilmaz, K. (2013). Comparison of quantitative and qualitative research traditions: Epistemological, theoretical, and methodological differences. European Journal of Education, Research, Development and Policy, 48(2), 311-325.

Zilber, T. B. (2006). The work of the symbolic in institutional processes: Translations of rational myths in Israeli high tech. Academy of Management Journal, 49(2), 281-303.

Zinovyeva, N., \& Bagues, M. (2015). The role of connections in academic promotions. American Economic Journal: Applied Economics, 7(2), 264-292.

Zupic, I., \& Cater, T. (2015). Bibliometric methods in management and organization. Organizational Research Methods, 18(3), 429-472.

Publisher's Note Springer Nature remains neutral with regard to jurisdictional claims in published maps and institutional affiliations. 